\title{
Roadmap Litter Monitoring in Dutch Rivers
}



van Emmerik, T.H.M. and Vriend, P., 2021. Roadmap Litter Monitoring in Dutch Rivers. Wageningen, Wageningen University, Report. 44 pp., https:// doi.org/10.18174/537439/

Keywords: anthropogenic litter, macrolitter, plastic pollution, macroplastic, monitoring

Approved for publication:

dr.ir. T.H.M. van Emmerik, Assistant Professor, Hydrology and Quantitative Water Management Group, Wageningen University

This work has been commissioned by:

Ministry of Infrastructure and Water Management

Directorate-General for Public Works and Water Management

Government of the Netherlands

This work is licensed under a Creative Commons Attribution 4.0 International License (CC BY 4.0). Wageningen University does not deliver printed versions of the Wageningen University reports.

(C) 2021 T.H.M. van Emmerik and P. Vriend

Wageningen University assumes no liability for any losses resulting from the use of the research results or recommendations in this report.

Wageningen University report

ISBN 978-94-6395-659-8

https://doi.org/10.18174/537439/ 


\section{Preface}

This report presents a Roadmap for a national macrolitter monitoring strategy in Dutch rivers. Anthropogenic litter, such as plastics, metal and glass, is pollution aquatic ecosystems. Litter from land is often transported through rivers into the world's oceans, where it eventually fragments and disintegrates over long time periods. In the meantime, the cause harm to ecosystems and human livelihoods. Planning of effective measures to counteract littering of rivers heavily depend on the availability of data. Developing a monitoring strategy on national scale is not trivial, as basic data is lacking and monitoring methods are available or harmonized. With the Roadmap we aim to provide a tool for decision-making and planning of steps required to develop a national monitoring strategy. This work has been commissioned by the Dutch Ministry of Infrastructure and Water Management, Directorate-General for Public Works and Water Management (Rijkswaterstaat). We thank Eric Copius Peereboom, Nadieh Kamp, Bert Bellert and Jilles Schippers for the smooth process and their input. We also thank the sixteen RWS experts who provided input during the expert panel survey. We also thank everyone who provided feedback on earlier versions of the Roadmap and this report.

Oberwilen $(\mathrm{CH})$, December 2020 


\section{Samenvatting in het Nederlands}

Zwerfafval (marco-afval, $>0.5 \mathrm{~cm}$ ) in rivieren heeft een negatieve impact op de staat van ecosystemen en de menselijke leefomgeving. Betrouwbare monitoringsdata op nationale schaal is cruciaal voor het optimaliseren van preventie-, mitigatie- en opruimstrategieën. Zwerfafvalmonitoring is op dit moment gelimiteerd tot rivieroevers op nationale schaal, en ad hocprojecten op lokale schaal. In dit rapport presenteren wij een Routekaar voor een nationale monitoringstrategie voor zwerfafval in en rondom Nederlandse rivieren. De routekaart biedt een aantal handvatten om specifieke projecten te plannen, categoriseren en prioriteren. Deze zullen op hun beurt bijdragen aan het beantwoorden van de grote open vragen omtrent zwerfafvalmonitoring in rivieren.

De Routekaart is gebaseerd op bijdragen van Rijkswaterstaatexperts en een literatuurstudie. Als een eerste stap hebben we vier hoofdoelen geformuleerd voor een nationaal monitoringsprogramma: (1) beleid, (2) kennis, (3) operationeel, en (4) oplossingen. Monitoring is noodzakelijk voor het ontwerpen en evalueren van beleidsmaatregelen, zoals het bepalen van passende grens- en streefwaarden voor hoeveelheden zwerfafval in riviercompartimenten (drijvend, oever, waterkolom, sediment). Observaties dragen ook bij aan het vergroten van de kennis over bronnen, hotspots en transportprocessen. Rijkswaterstaat (RWS) heeft als beheerder van de rivieren de verantwoordelijkheid voor het meten van hydrologische en waterkwaliteitsvariabelen. Zwerfafvalmonitoring kan worden gezien als additionele intrinsieke taak. Tot slot is monitoring een cruciaal onderdeel voor de evaluatie van de effectiviteit van elke genomen maatregel, van beleidsmaatregelen tot opruimstrategieën.

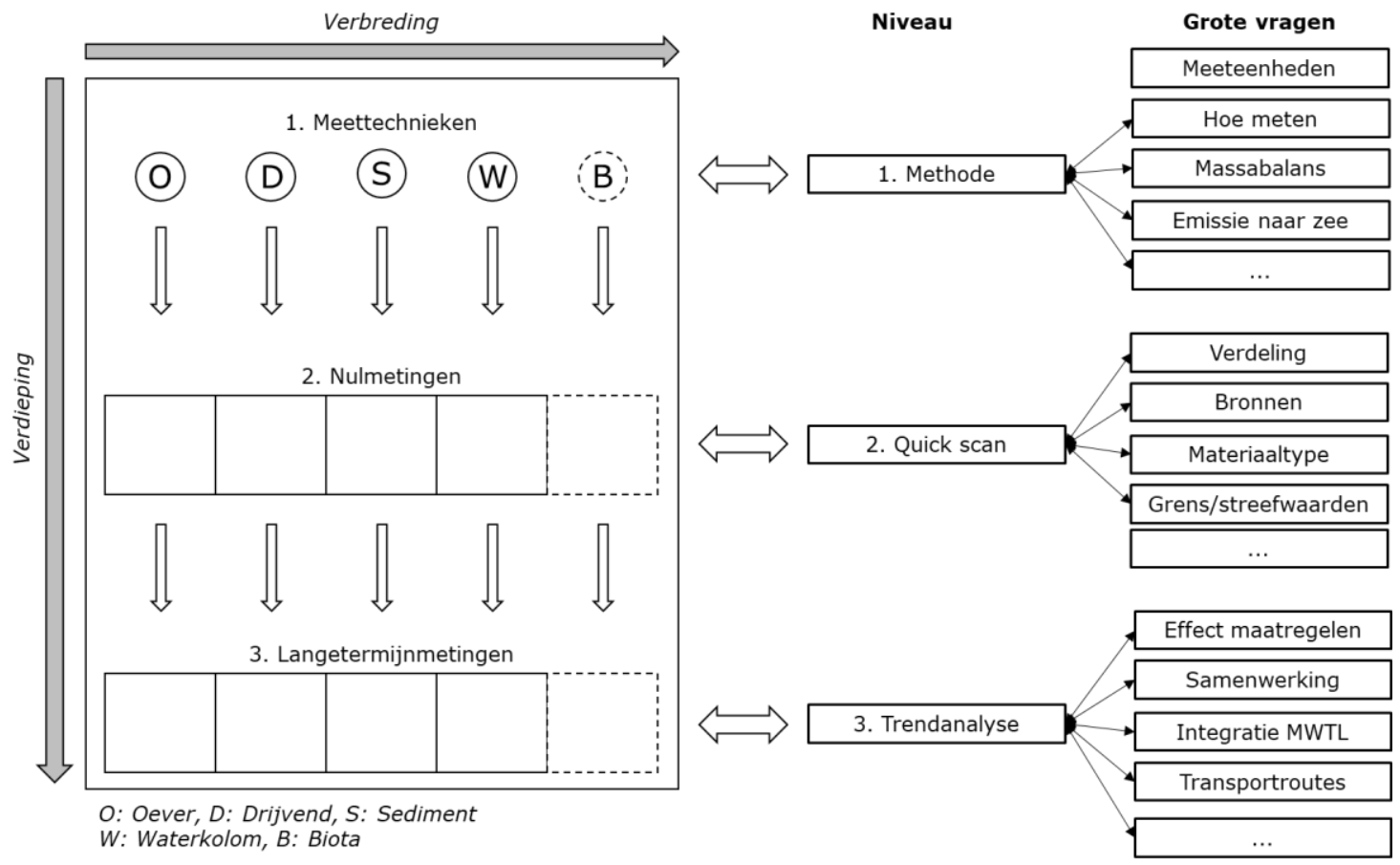

Figure 1: De Routekaart voor zwerfafvalmonitoring in en rondom Nederlandse rivieren.

De Routekaart bestaat uit drie niveaus. Niveau 1 focust op monitoringsmethoden. Niveau 2 focust op de Nationale Nulmeting. Niveau 3 focust op lange-termijnmonitoring. Op elk niveau kunnen specifieke vragen beantwoord worden. Specifieke projecten kunnen bijdragen aan het behalen van een volgend niveau (verdieping), of het toevoegen van extra riviercompartimenten (verbreding). De Routekaart kan worden gebruikt in twee richting. Ten eerst kan afgelezen worden welke vragen beantwoord kunnen worden na het afronden van een specifiek project. Ten tweede kan de route worden uitgestippeld die 
nodig is om tot het antwoord te komen op een specifieke vraag. Om bijvoorbeeld de effectiviteit van maatregelen te bepalen (niveau 3), moeten eerst de projecten voor (1) bepalen meetmethoden, (2) nationale nulmeting en (3) langetermijnmonitoring worden afgerond.

Op basis van de Routekaart hebben we 24 specifieke projecten geformuleerd om de open vragen te beantwoorden. Deze projecten zijn vervolgens geprioriteerd en geclusterd, als extra suggestie voor de volgorde van uitvoering van de projecten. We hebben zes clusters gedefinieerd: (1) innovatief meten, (2) monitoringsprotocollen, (3) nationale nulmeting, (4) langetermijnmonitoring, (5) samenwerking \& integratie, en (6) richtlijnen \& oplossingen. Op de korte termijn (1-3 jaar) hebben clusters 1 en 2 de hoogste prioriteit. Deze projecten zullen geschikte monitoringmethoden en -protocollen opleveren voor de volgende fases. Op de middellange termijn (3-5 jaar) zal de prioriteit uitgaan naar de projecten binnen cluster 3. Dit levert een eerste integraal beeld op van de hoeveelheid zwerfafval in de verschillende riviercompartimenten. Tegelijkertijd kan ook een start gemaakt worden met clusters 5 en 6 om te zorgen dat er vroegtijdig wordt samengewerkt op lokale, nationale en internationale schaal. Op de lange termijn ( $>5$ jaar) zal er vooral focus blijven op de langetermijnmonitoring, om te zorgen van betrouwbare hotspotidentificatie, trendanalyses en evaluatie van maatregelen.

Met de Routekaart bieden een we een nieuw instrument ter ondersteuning van het maken van beslissingen en het plannen van specifieke projecten. De voorgestelde lijst met vragen en projecten is niet definitief. De Routekaart is ontworpen als flexibel raamwerk waarin elementen kunnen worden toegevoegd of verwijderd naar aanleiding van nieuwe inzichten, beschikbare middelen en andere relevante verandering. Zwerfafvalmonitoring is een iteratief proces en de Routekaart draagt hopelijk bij aan het zetten van een eerste stap in de goede richting.
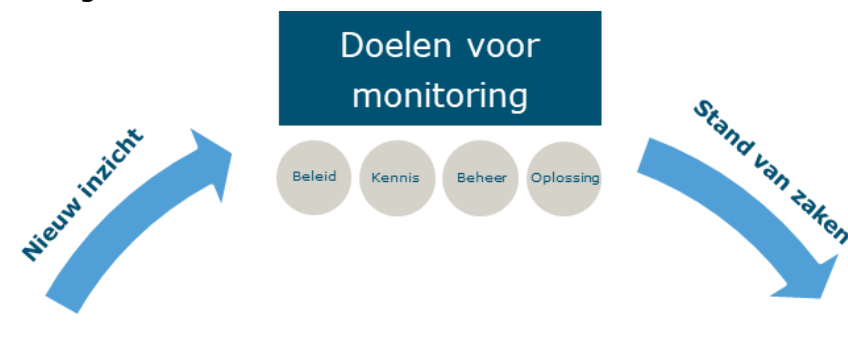

Tijdspad

\section{Grote vragen}
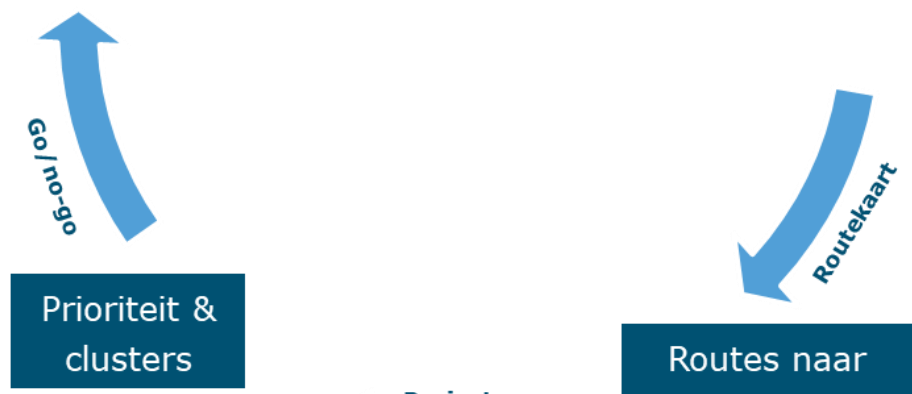

Routes naar

antwoorden

Figure 2: Cyclus van doelen stellen, grote vragen definiëren, routes naar antwoorden planning, projecten prioriteren en clusteren, plannen en uitvoeren van projecten. Dit benadrukt de iteratieve aard van zwerfafvalmonitoring in rivieren. 


\section{Summary in English}

Riverine macrolitter $(>0.5 \mathrm{~cm})$ has negative impact on ecosystem health and human livelihood. Reliable monitoring data on national scale is crucial for optimizing prevention, mitigation and litter reduction strategies. To date, monitoring in the Netherlands are limited to riverbanks and ad hoc projects on local scales. In this report we present the Roadmap for a national litter monitoring strategy in Dutch rivers. The Roadmap provides a set of tools to plan, categorize and prioritize specific projects required to answer open questions.

The Roadmap is based on expert input and a literature review. As a first step, we identified four main goals for a national monitoring program: (1) policy, (2) knowledge, (3) operations, and (4) solutions. Monitoring is required to design and evaluate policy measures, such as the introduction of appropriate norm and target values for macrolitter in river compartments (i.e. floating, riverbanks, water column, sediment). Observations will also increase the understanding of litter sources, sinks, and transport pathways. Rijkswaterstaat (RWS) is the responsible stakeholder for the main water ways, and has the task to measure hydrological and water quality variables. Litter monitoring may be considered as additional operational task. Finally, monitoring is a crucial component to evaluate the efficacy of any measures, from policy to litter collection solutions.

The Roadmap consists of three level of knowledge. Level 1 focuses on monitoring methods. Level 2 focuses on Baseline measurements of the river components. Level 3 relates to long-term monitoring. At each level specific questions can be answered. Specific projects can contribute to reaching a new level (extension) or including additional river compartments (expansion). The Roadmap can be read in two directions. First, one can read what questions can be answered after completion of a specific project. Second, one can read what steps are required to solve a specific question. For example, to evaluate the effect of measures to reduce floating litter, one needs to (1) develop of monitoring methods, (2) conduct baseline measurements, and (3) perform long-term monitoring of floating litter.

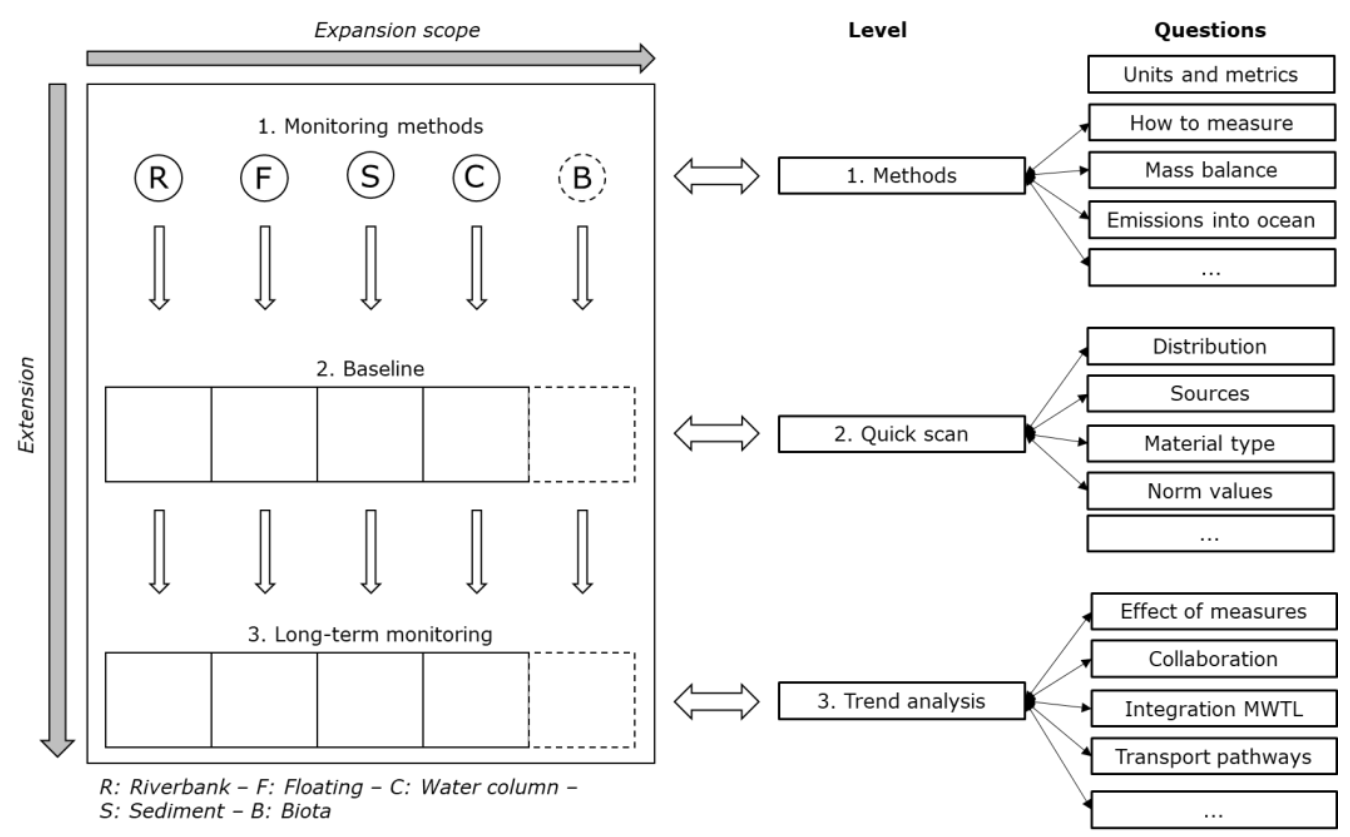

Figure 3: The Roadmap for national riverine litter monitoring in Dutch rivers. 
Based on the Roadmap we identified 24 specific projects that are required to address all remaining open questions. These projects have been prioritized and clustered, to provide additional suggestions on the order of execution of the project. We defined six clusters: (1) innovative sensing, (2) monitoring protocols, (3) national baseline, (4) long-term monitoring, (5) collaboration \& integration, and (6) guidelines \& solutions. On the short term (1-3 years), cluster 1 and 2 have the highest priority. These projects will deliver suitable monitoring tools and protocol for the next phase. On the medium term (3-5 years), projects related to cluster 3 should be prioritized to arrive at a first order of magnitude estimate of litter in each river component and its relative importance. In parallel, a start can be made with clusters 5 and 6 to allow smoothen the path for collaboration and integration of monitoring at local, national and international scales. On the long term ( $>5$ year) the main focuses will remain with the long-term monitoring efforts, to allow for reliable hotspot mapping, trend analyses, and evaluation of measures.

With the Roadmap we aim to provide a new tool to support decision-making and planning of specific projects. The specific questions and projects are not exhaustive, and the Roadmap is a flexible framework that allows to add and remove elements based on new insights, the available resources, and other relevant changes. Riverine litter monitoring remains an iterative process, and we hope that the Roadmap will contribute to taking a first step in the right direction.

\section{Monitoring goals}
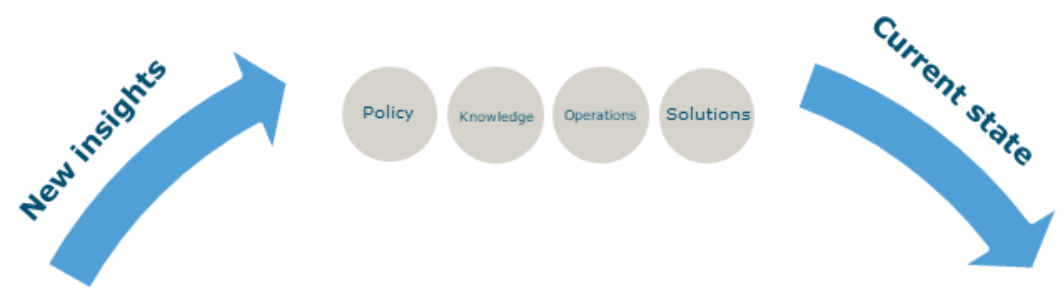

\section{Timeline}
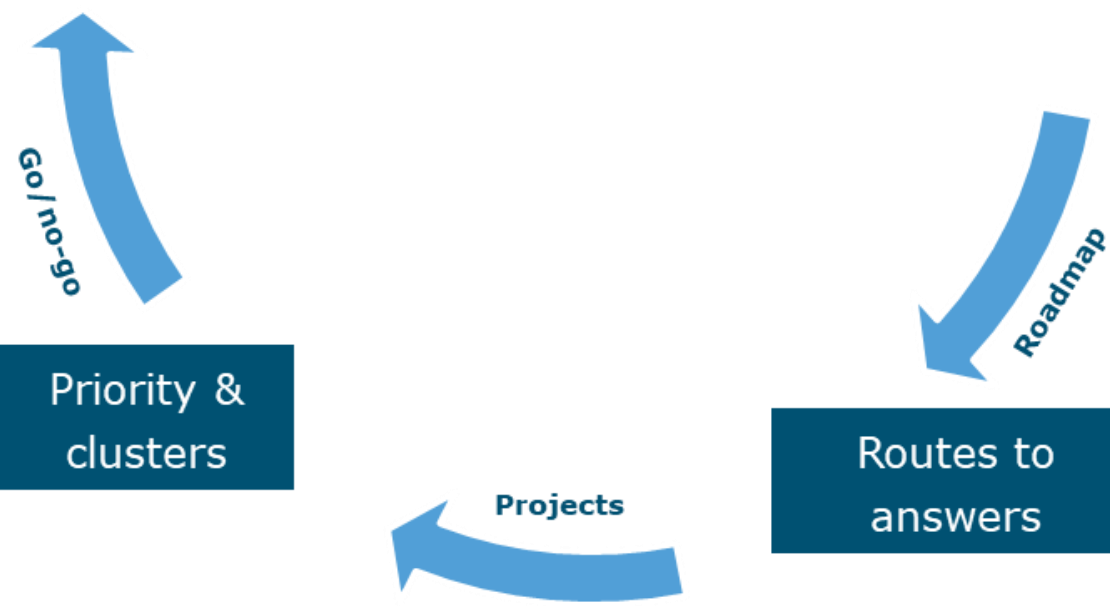

\section{Routes to}

\section{answers}

Figure 4: The cycle of defining monitoring goals, formulating open questions, selecting routes to answers, prioritizing and clustering projects, and planning and executing projects. This emphasizes the iterative nature of riverine litter monitoring. 


\section{Content}

Preface 4

Samenvatting in het Nederlands $\quad 5$

Summary in English 7

1 Introduction 11

1.1 Why riverine macrolitter matters 11

1.2 Litter transport from source to sink 11

1.3 Additional impact of macroplastic 11

1.4 Need for a Roadmap 12

1.5 Approach 12

1.6 How to read this report 12

$2 \quad$ Background information 13

$2.1 \quad$ Defining macrolitter 13

2.2 Defining river compartments 14

2.3 Key figures on macrolitter in Dutch rivers 15

2.3.1 Floating litter $\quad 15$

2.3.2 Riverbank litter 15

$3 \quad$ Recent developments in macrolitter monitoring 17

3.1 Developments in the Netherlands $\quad 17$

3.1.1 Schone Riveren $\quad 17$

3.1.2 Regional citizen science projects $\quad 17$

$\begin{array}{lll}3.1 .3 & \text { Litter traps } & 18\end{array}$

3.1.4 Litter free rivers and streams (LIVES) 18

3.2 International developments 19

3.2.1 RIMMEL, Europe 19

3.2.2 Plastic Pirates, Germany 19

3.2.3 Emissions of the Ems, Weser and Elbe, Germany 20

3.2.4 National Baseline, Indonesia $\quad 21$

3.2.5 Echo sounding for underwater litter monitoring, Netherlands and Spain 21

$\begin{array}{ll}3.3 & \text { Summary table of recent developments }\end{array}$

$4 \quad$ Giving direction - Goals for riverine litter monitoring 23

$\begin{array}{lll}4.1 & \text { Expert survey } & 23\end{array}$

4.2 Results of the expert survey 24

4.3 Four main goals 26

4.4 Short, medium and long-term goals 26

4.5 The open questions 28

$5 \quad$ Roadmap for a national riverine litter monitoring strategy 29

5.1 Structuring questions 29

5.2 Adding flexibility 29

5.3 The Roadmap for riverine litter monitoring in Dutch rivers 30

5.4 The Roadmap as dashboard 32

$6 \quad$ Towards a national monitoring strategy 33

6.1 Project proposals 33

6.2 Prioritizing projects 34 
6.3 Clustering projects 35

6.4 Timeline for national monitoring strategy 36

6.5 Riverine litter monitoring is an iterative process 37

$7 \quad$ Conclusions and recommendations 39

7.1 Conclusions 39

7.2 Recommendations 39

$\begin{array}{ll}\text { References } & 41\end{array}$

Annex 1 Rijkswaterstaat Expert Survey $\quad 43$ 


\subsection{Why riverine macrolitter matters}

Anthropogenic litter in aquatic environments is an emerging environmental risk, as it may negatively impact ecosystems, endangers aquatic species, and causes economic damage (van Emmerik \& Schwarz, 2020). Rivers are assumed to play a crucial role in transporting land-based litter to the world's oceans (Schmidt et al., 2017). However, rivers and their ecosystems are also directly affected by anthropogenic litter (van Emmerik \& Schwarz, 2020). To better quantify global litter transport and to effectively reduce sources and risks, a thorough understanding of sources, transport, fate and effects of riverine litter debris is crucial.

\subsection{Litter transport from source to sink}

Litter enter river systems through either natural transport processes or through direct dumping. Natural transport can be caused by wind or rainfall-driven surface runoff (Bruge et al., 2018). Direct dumping can include illegal dumping sites (Rech et al., 2015; Mihai, 2018) and unintentional disposal at recreational locations, such as riverbanks (Kiessling et al. 2019). Once in a river, litter transport and accumulation are influenced by hydrological (water level, flow velocity, discharge) and anthropogenic factors (hydraulic infrastructure, clean-up activities, navigation).
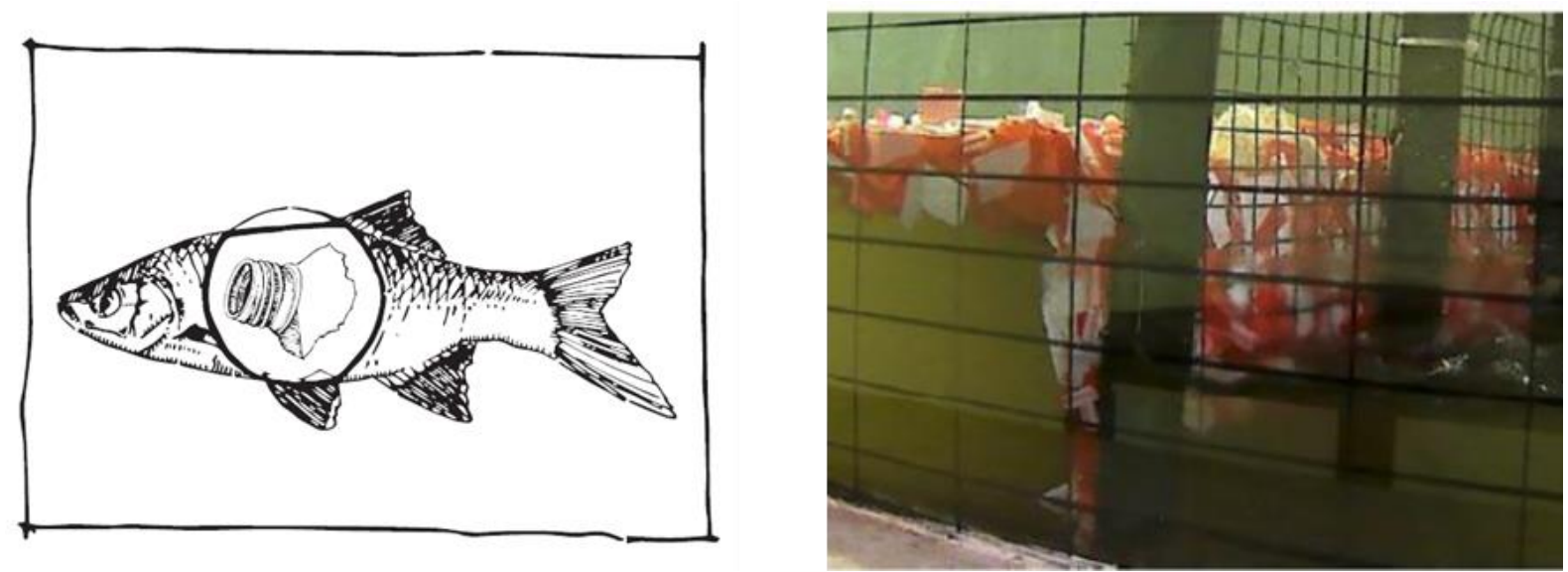

Figure 5: Examples of negative impact from macrolitter in river systems. Left: ingestion of plastic by freshwater species. Right: accumulation of plastic debris at urban water infrastructure, resulting in faster and higher water level increase compared to organic material, leading to additional urban flood risk.

Litter items have been observed in all compartments of the river system. Depending on the litter item material type, state of degradation and antecedent hydrological regime, items can be mobile in the water column or (temporarily) accumulated. Riverine litter transport consists of floating items at the surface, suspended litter along the water column and transport over the riverbed. Accumulation occurs in biota, sediment, riparian vegetation and on riverbanks. Monitoring litter in river systems can help identifying sources of litter. Known sources include sewage outlets from wastewater treatment plants, recreational activities in the vicinity of riversides, and areas with high urban activities (van Emmerik \& Schwarz, 2020).

\subsection{Additional impact of macroplastic}

Plastic pollution makes up the largest part of anthropogenic litter in river systems. Although exact percentages vary per river system and river compartment, observations in Dutch rivers found that plastics account for almost $90 \%$ of the litter items (van Emmerik et al., 2020). Macroplastic $(>0.5 \mathrm{~cm}$ ) cause addition environmental risk. Riverine macroplastics are estimated to be the main source of marine plastic pollution, causing additional harm to species and damage to shipping vessels. Recent work demonstrated that a substantial amount of plastic is found below the surface or at the ocean seafloor (Peng et al., 2020; Pabortsava \& Lampitt, 2020), where it will most likely never be removed. Besides anthropogenic stressors 
on the environment, such disappeared plastics are also a loss of resources. Finally, riverine macroplastics are also considered to be the major source of microplastics in freshwater systems. Reducing macroplastic pollution will therefore have a direct positive effect on the abundance of microplastics in rivers too.

\subsection{Need for a Roadmap}

The need for reliable litter data is clear. Only through adequate monitoring efforts, prevention, mitigation and litter reduction strategies can be optimized and implemented. Unfortunately there are still many unknowns with respect to what measurement methods, protocols, and approaches should be chosen for a national monitoring strategy. Basic data on the abundance, variation and composition of riverine litter is lacking, hampering the planning of next steps in designing a monitoring strategy. To overcome these issues, we present a Roadmap for riverine litter monitoring in Dutch rivers. By defining, structuring and categorizing the open questions and challenges, we present a simple framework to support planning of specific projects that will contribute to developing a national monitoring strategy. The Roadmap can be used in two directions. First, it can be seen what questions will be answered after completing specific projects. Second, one can see the steps required to arrive at an answer for a specific question.

\subsection{Approach}

The Roadmap is based on input from a Rijkswaterstaat (RWS) expert panel, and a synthesis of recent (scientific) literature. The expert survey was conducted to receive input on the goals, questions and priorities of a future monitoring strategy. For the literature review we used studies from the Netherlands, Europe and beyond, to construct a view of the current state of the science and the available methods. The expert survey and literature review were combined to formulate key questions that remain unsolved. The Roadmap structured, categorized, and prioritized these question into clusters of concrete project proposals that can be executed on the short, medium and long term.

\subsection{How to read this report}

In chapter 2 we present some background information on riverine litter, including definitions and examples. We provide additional key figures on what it is known about litter abundance in Dutch rivers. Chapter 3 discusses recent developments in riverine litter monitoring in the Netherlands and beyond. We discuss outcomes from citizen science approaches, large-scale monitoring efforts and technological advances. Chapter 4 presents the outcomes of the expert survey, and presents the list of open key questions. Chapter 5 presents the Roadmap, and discusses how this can be used to plan future projects and assess the current state of knowledge. Chapter 6 provides suggestions on the way forward, introducing specific project proposals, project clusters, and a timeline for future work. In Chapter 7 we present the conclusions and a list of recommendations. 


\subsection{Defining macrolitter}

Litter pollution is generally characterised based on its size and material type. Litter is characterized on size because it influences the potential sources, transport mechanisms, and detection methods of litter. This paper will follow the terminology and dimensions as proposed by van Emmerik \& Schwarz (2020), which divides litter in four size groups ranging from nano- $(<0.1 \mu \mathrm{m})$, to micro- $(0.1 \mu \mathrm{m}-5 \mathrm{~mm})$, to meso- $(5 \mathrm{~mm}-5 \mathrm{~cm}$ ), to macrolitter $(>5 \mathrm{~cm}$ ) (Figure 6$)$. Size groups are often aggregated, where nanoand microlitter are grouped into microlitter, and meso- and macrolitter grouped into macro litter. Secondly, litter is characterized based on the material which makes up the litter. A first distinction to make is whether the litter is organic or inorganic. Most studies exclude organic litter since this has not been introduced through anthropogenic disturbance of ecosystems, this report excluded organic litter as well. Secondly, research on anthropogenic litter pollution is often solely focused on plastic pollution since on a global scale this is the most abundant material type. This report expands the scope of analysis and includes other materials such as metals, glass, textiles, papers, and rubber (Figure 7).

\section{Nano $<0.1 \mu \mathrm{m}$}

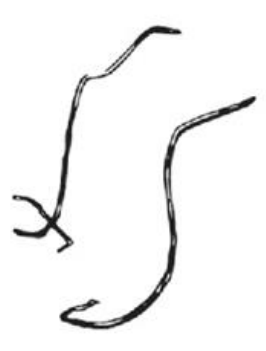

$\underset{0.1 \mu M-5 M M}{\text { Micro }}$

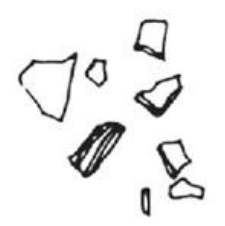

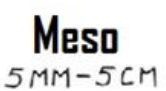

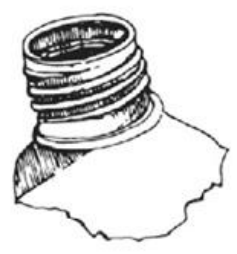

Macro
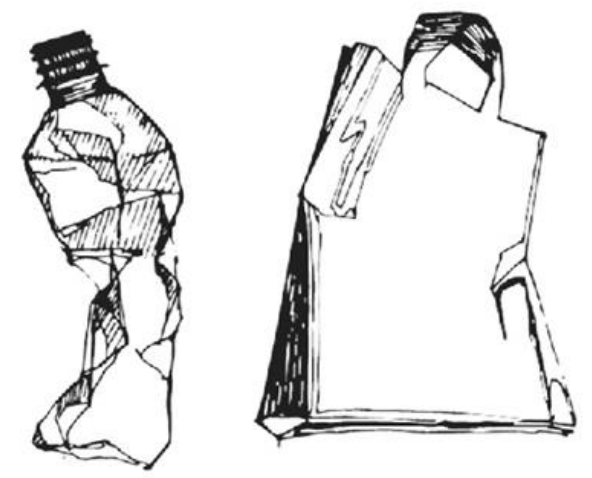

Included in this study

Figure 6: Litter classification based on size, with examples of typical items found for each size range for plastic litter, adapted from van Emmerik \& Schwarz (2020).

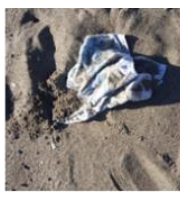

Textile

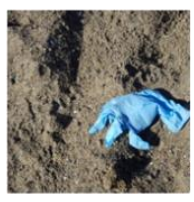

Rubber

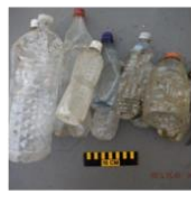

Plastic
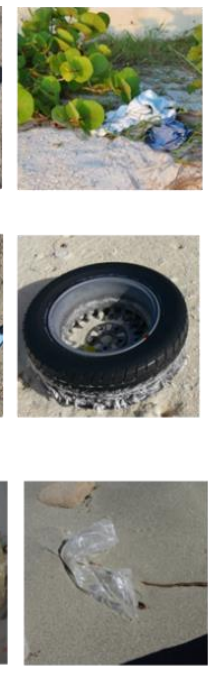

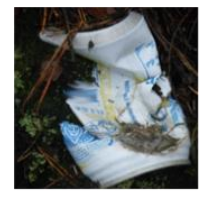

Metal

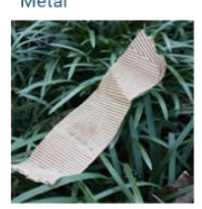

Paper
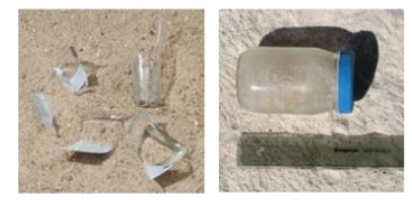

Figure 7: Examples of typical anthropogenic litter, including textile, metal, rubber, paper, plastic and glass. 


\subsection{Defining river compartments}

Riverine litter transport is influence by hydrological factors such as water level, flow velocity, and river discharge (van Emmerik \& Schwarz, 2020). The transport of riverine litter is not instant but is instead a continuous cycle of temporary deposition and resuspension in the water column. The location of litter in river systems directly influences the methods that can be used to detect and quantify it. It is therefore useful to define these locations within the river. Van Emmerik \& Schwarz (2020) define five compartments of litter transports (Figure 8). Three compartments act as temporary depositional zones of litter in river systems, these compartments being litter deposited in sediment, ingested by biota, and litter deposited on riverbanks. River compartments that transport riverine litter include floating litter, litter suspended in the water column, and riverbed transport of river.

Methods to quantify litter differ for each compartment, and these methods are different stages of development. Floating macrolitter and litter deposited on riverbanks are most frequently quantified. The methods to quantify litter in these river compartments are mature in their development, are easy to perform and require little equipment (e.g. van Emmerik et al., 2018; Vriend et al., 2020a), which leads to a wide scale application of them. Methods to quantify litter in sub-surface compartments (e.g. water column, riverbed, in biota) are less often applied, which has led to these methods being less developed.

Data on litter in all river compartments is required to effectively quantify plastic pollution in the riverine environment. Research quantifying litter pollution is not mostly focused on one or two riverine compartments at the same time. This data is relevant but misses the full picture of litter pollution. To gather data that can aid the design of effective mitigation and removal policies, litter in all river compartment should be quantified. First efforts to do so have recently been published by Schöneich-Argent et al. (2020), who quantified plastic deposition and exports for three major rivers in Germany.

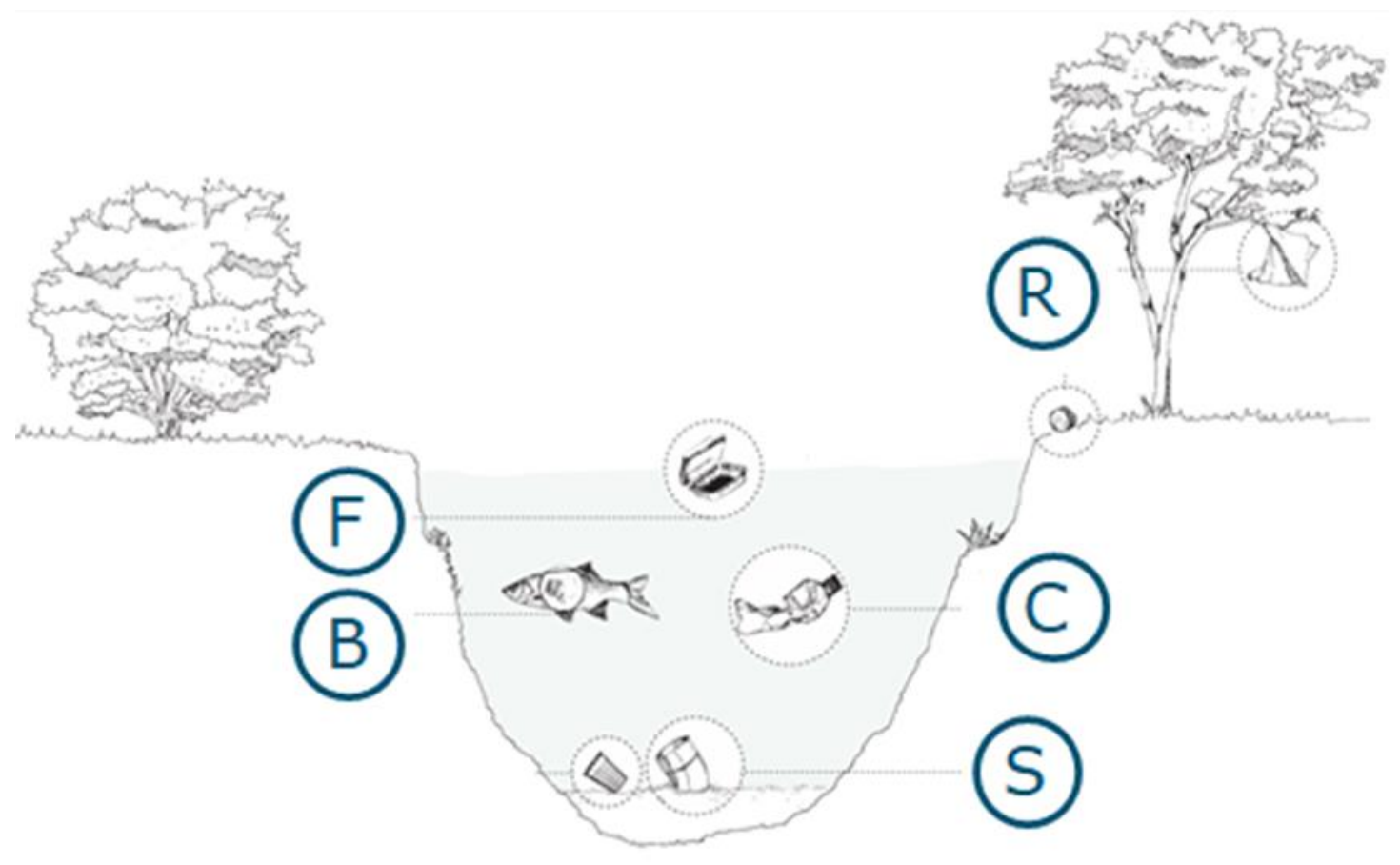

Figure 8: Overview of river compartments in which riverine litter can reside, where $R$ represents litter deposited on riverbanks, $F$ is floating litter, $B$ is litter in biota, $C$ is litter suspended in the water column, and $S$ represents riverbed transport and deposition (adapted from van Emmerik \& Schwarz, 2020) 


\subsection{Key figures on macrolitter in Dutch rivers}

\subsubsection{Floating litter}

Several studies have been published on floating riverine litter transport in the Dutch Rhine delta. Estimates of plastic exports by Dutch rivers range between $1.3-6300 \mathrm{~kg}$ per day (Vriend et al., 2020b, van der Wal et al., 2015; Lebreton et al., 2017). The large range in estimates indicates the uncertainties associated with the current data. Most of the floating litter found in the Dutch river delta is plastic (van der Wal et al., 2015). Frequently found plastic polymers include polystyrene (PS), polyethylene terephthalate (PET), expanded polystyrene (EPS), and soft and hard polyolefin (POsoft, POhard) (Figure 9, Vriend et al., 2020b).

Data on floating litter in the Dutch river delta was gathered through different methods. Van de Wal et al. (2015) deployed nets from a stationary pontoon along the riverbank and extrapolated this to the full river width to quantify floating litter transport. Vriend et al. (2020b) combined visual observations from the Erasmus bridge in Rotterdam with a sample taken from a nearby litter trap (Shoreliner deployed by Tauw) to determine plastic transport.

Floating litter has also been quantified in the cities of Leiden and Wageningen (Tasseron et al., 2020). Floating litter concentrations in these cities were found to be 111-133 items per kilometre of canal, with pollution hotspots around more populous areas within the cities.
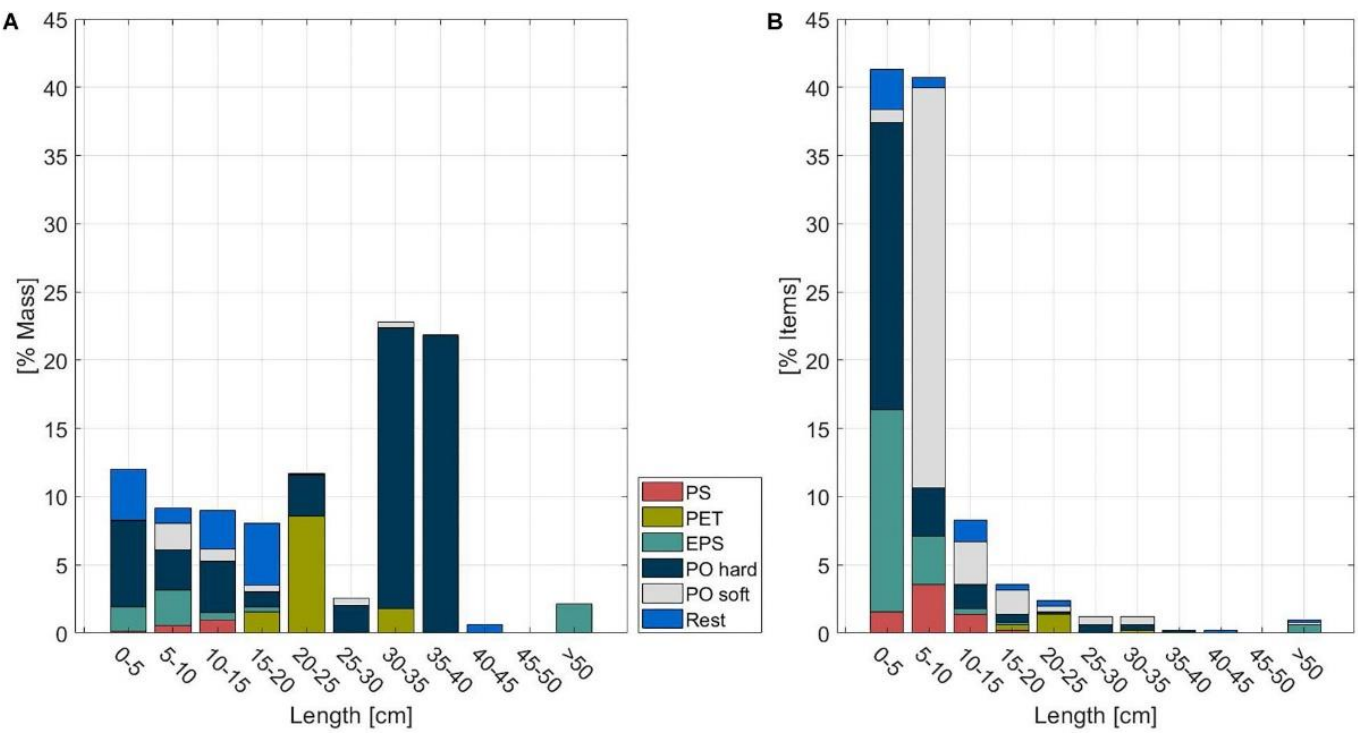

Figure 9: Plastic composition as collected in the litter trap called the Shoreliner in Rotterdam, as (A) a function of mass and $(B)$ the plastic composition as collected in the Shoreliner as a function of number of items. Polymers found in the sample include polystyrene (PS), polyethylene terephthalate (PET), expanded polystyrene (EPS), and soft and hard polyolefin ( $\left.P O_{\text {soft, }} P O_{\text {hard }}\right)$ (Vriend et al., $2020 b)$.

\subsubsection{Riverbank litter}

Riverbank macrolitter has been quantified by multiple initiatives across The Netherlands. Results published in peer reviewed literature give an indication of the composition and density of litter found on Dutch riverbanks, as well as hotspots in which relatively large quantities of litter accumulate. Van Emmerik et al. (2020b) reported an average of 2060 litter items per kilometre of riverbank. Similar litter densities of 04000 items per km were found during riverbank litter monitoring near Rotterdam (van Emmerik et al., 2020c). Frequently found items include plastic fragments, food wrappings, caps and lids, as well as cotton swabs (Figure 10, van Emmerik et al., 2020b). 85.1\% of the total items found on Dutch riverbanks ( $n=$ 152,415 ) were made of plastic (van Emmerik et al., 2020b). Hotspots were found to be centred around cities (e.g. Maastricht, Nijmegen, Arnhem) and in Biesbosch national Park (van Emmerik et al., 2020 b). 

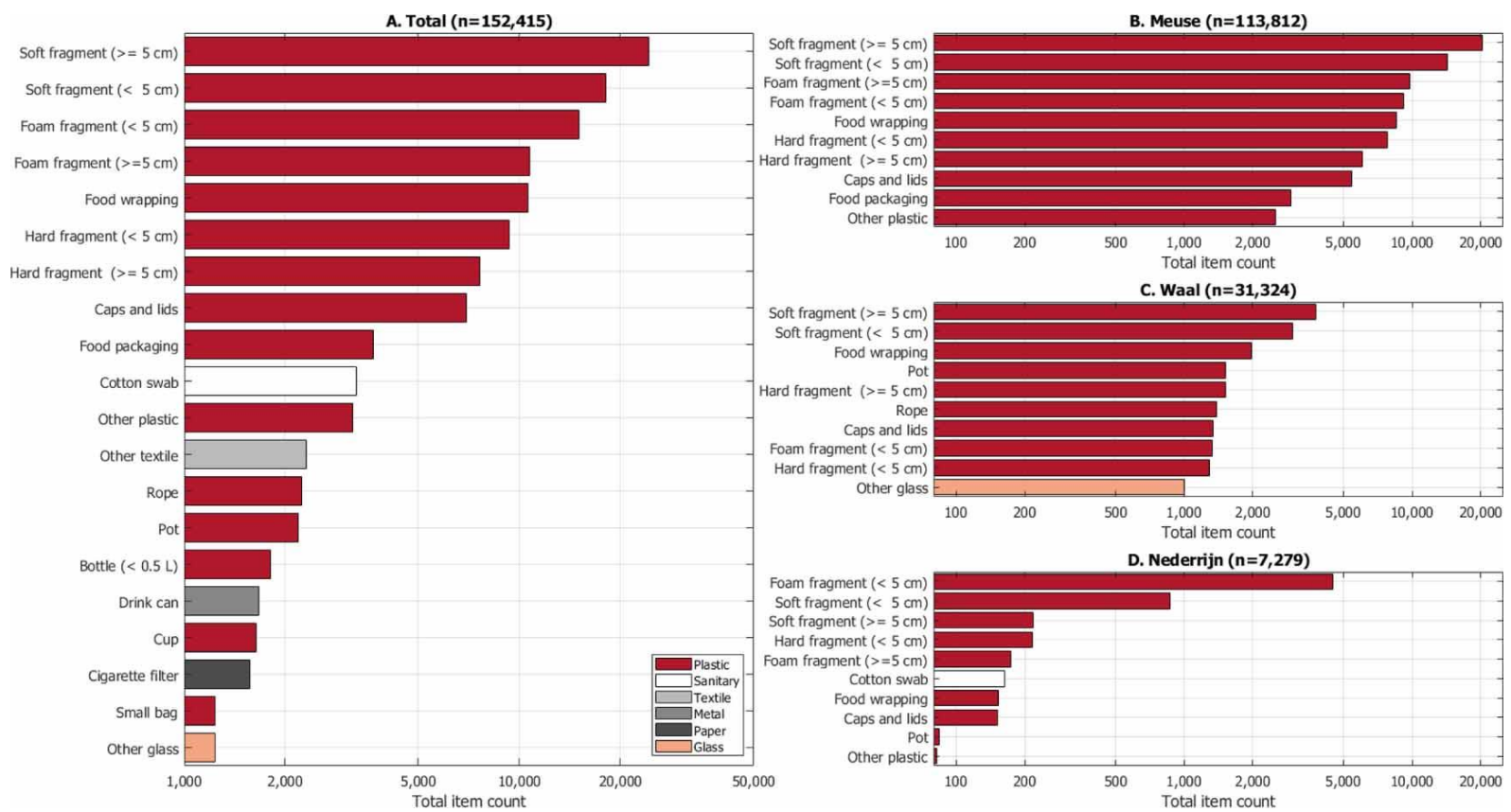

Figure 10: A. Top 20 riverbank items in the Rhine-Meuse delta, and the top 10 riverbank items for the B. Meuse, C. Waal (Rhine), and D. Nederrijn (Rhine) rivers. The colors of the bars indicate the item parent category (plastic, rubber, textile, paper, wood, metal, glass, sanitary and medial items) (adapted from van Emmerik et al., 2020b). 


\section{$3 \quad$ Recent developments in macrolitter monitoring}

\subsection{Developments in the Netherlands}

\subsubsection{Schone Riveren}

Schone Rivieren is a project that aims to monitor litter pollution on riverbanks of the Dutch Rhine-Meuse delta. To do so, a collaboration of Stichting de Noordzee (Northsea foundation) and IVN Natuureducatie (IVN Nature education) have adapted the OSPAR beach litter identification protocol to be used for riverbank litter (van Emmerik et al., 2020a). Schone Rivieren samples riverine litter at 212 unique locations twice per year, once in spring and once in fall (Figure 11). The help of citizen scientists is used to allow for the sampling of the large number of locations in a short time period. Monitoring of litter using this method was started in 2017 and is planned to be continued for the coming years. Findings of the riverbank monitoring done by the Schone Rivieren project were recently published (van Emmerik et al., 2020b). These results indicate that plastic bottles, food wrappings and packaging, lids, and cotton swabs are most abundant items on Dutch riverbanks. Moreover, data gathered identifies several litter hotspots, most notably where rivers cross the border into the Netherlands, around cities, and in the Biesbosch National Park.

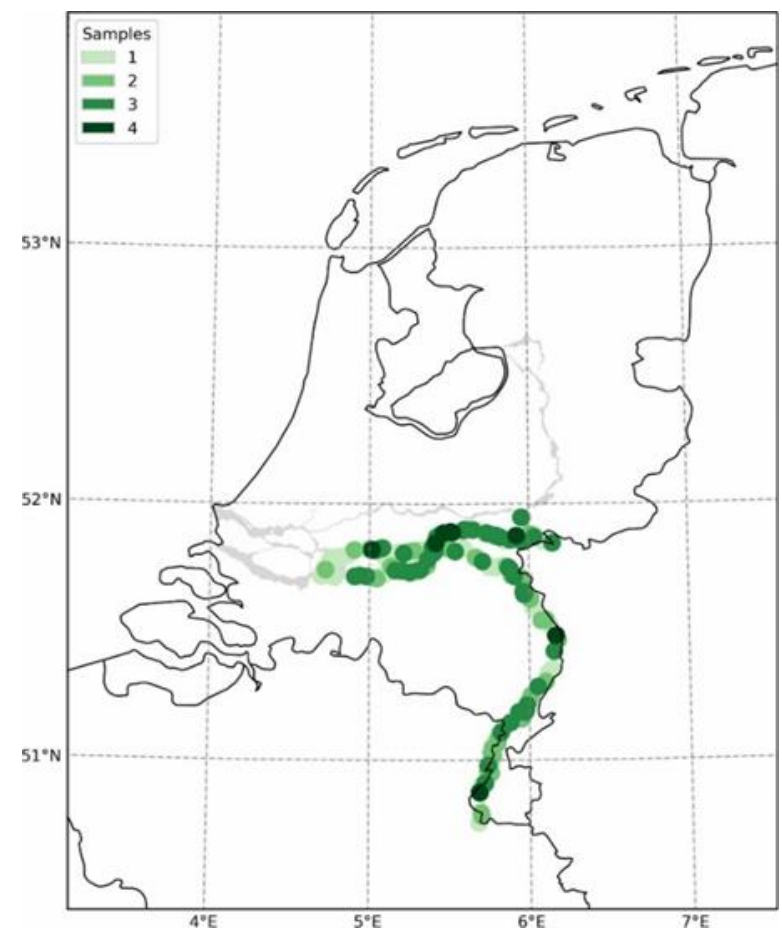

Figure 11: Overview of measurement locations analysed for riverbank litter by the Schone Rivieren project in the period 2017-2019, with samples indicating the number of times samples were taken at the location (adapted from van Emmerik et al. 2020a)

The Schone Rivieren project is an important reference project for national riverine litter monitoring strategies in the Dutch river delta since it is an example of how a fully developed project for a specific river compartment may look like (see Vriend et al., 2020a for more examples for riverbank litter quantification projects). Moreover, RWS can decide to incorporate the Schone Rivieren project in the Dutch riverine litter monitoring strategy, or adapt the method used in the project for their specific future needs.

\subsubsection{Regional citizen science projects}

Projects that quantify riverine litter on local scale using citizen scientists include the Plastic Spotter project, Scouts4Science, Clearrivers, and the projects launched by the universities of applied sciences of Rotterdam and Zeeland. The aims of these projects are to quantify litter pollution and to clean up the trash as well. The plastic spotter project lets citizen scientist map floating litter pollution in (mostly) urban environments using the Crowdwater app (Tasseron et al., 2020). The data gathered with this method is open access and allows for the mapping of litter hotspots and the analysis of the composition of the litter. The Crowdwater app has been tested on a larger scale in the cities of Leiden and Wageningen (Figure 12), but the citizen 
science aspect allows it to be applied on any surface water. Similarly, the university of applied sciences of Rotterdam launched a project together with the university of Wageningen to monitor macroplastic pollution on riverbanks of the lower reaches of the Rhine using the Crowdwater app (van Emmerik et al., 2020c). The Crowdwater is presented as a reference project since it is a proven method to quantify floating litter in both urban and rural environments. Moreover, the Crowdwater app is open source and could therefore easily be incorporated in a national litter monitoring strategy, saving costs on the development of an app.
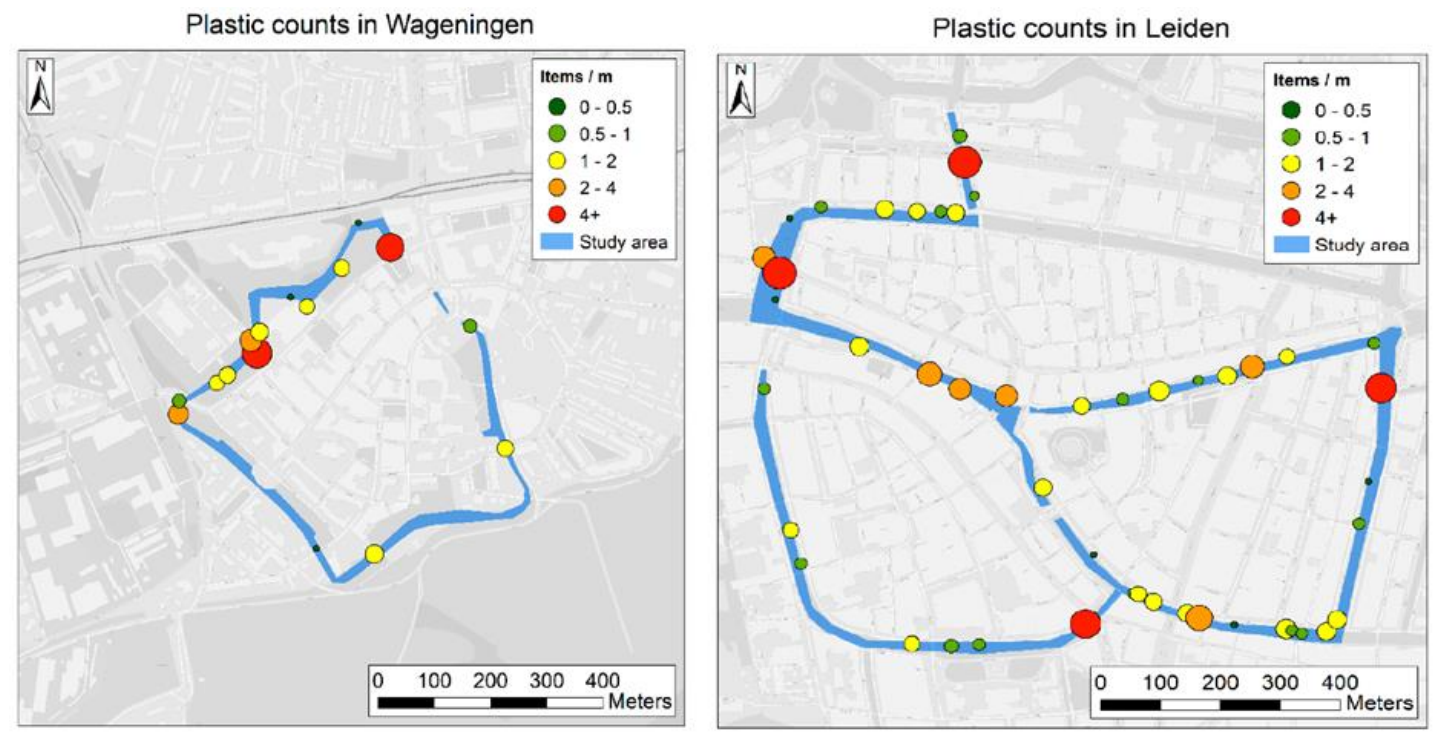

Figure 12: Examples of litter hotspot mapping done in the urban environments of Leiden and Wageningen. Adapted from van Tasseron et al. (2020).

Scouts4Science is a project in which Dutch scouts help with data collection for scientists. They have helped with gathering data on plastic pollution in the Zeeland province. They have gathered data on floating and riverbank plastic pollution in and around the Ooster- and Westerschelde (Scouts4Science. n.d.). The university of applied sciences Zeeland is doing similar research on the riverbanks of the Schelde. Lastly, Clear Rivers performs research on floating and riverbank litter in Rotterdam, near the river mouth of the Nieuwe Maas (New Meuse) river. They perform riverbank cleanups with volunteers and have installed litter traps to catch riverine waste (Clear Rivers, n.d.). These regional project show that a wide range of regional projects are already applied in the Dutch river delta. Data gathered through this project could aid the design of future national monitoring strategies or it can be decided to integrate these initiatives in national monitoring strategies.

\subsubsection{Litter traps}

A handful of litter traps have been developed and deployed in the Netherlands. For example, the Great Bubble Barrier (GBB) has been recently installed in the canals of Amsterdam. The GBB creates a screen of bubbles from the riverbed upwards. This screen creates a barrier which traps litter, but it does not hinder other water users (Great Bubble Barrier, n.d.). Besides the GBB, a large variety of litter traps have been developed that passively collect litter. For example, Tauw developed a litter trap which they call the Shoreliner, which have so far been deployed in Rotterdam and in the Ijssel river (Landman \& Pikaar, 2019), Noria has developed a litter trap that has been tested in Borgharen (Noria, n.d.), Clear Rivers developed a trap that they have deployed in the Netherlands, Belgium, and Indonesia (Clear Rivers, n.d.), and All Seas have developed a litter trap called Catchy which they have installed near Rotterdam (All Seas, n.d.). Litter traps are important reference projects since besides their primary task of removing litter they can also be used to gain valuable data on the composition of floating riverine litter (Vriend et al. 2020).

\subsubsection{Litter free rivers and streams (LIVES)}

Litter free rivers and streams (LIVES) is a cross-border initiative with the aim of reducing plastic waste in the Meuse catchment area by $50 \%$ (Interreg, n.d.). The project is split in four steps that will have to be set to reach this goal, which include 1 ) analysis of the problem, 2) taking steps to reduce plastic waste, 3) 
concluding cross-border agreements to reduce plastic pollution, and 4) ensuring that these agreements are known by all relevant stakeholders. The LIVES project is special in this regard since it directly links the monitoring of plastic waste with short- and long-term actions to reduce its presence and does so on a cross-border scale. The LIVES project is a key reference project since it shows that cross-boundary cooperation is required to get a full overview of riverine litter pollution, as well as for reducing the presence of riverine litter. This project can also be used as a guide to how possible future cooperation in a national monitoring strategy may look like.

\subsection{International developments}

\subsubsection{RIMMEL, Europe}

The RIMMEL (Riverine and Marine floating macro-litter Monitoring and Modelling of Environmental Loading) project was initiated by the European Commission joint research centre with the goal to quantify exports of floating macrolitter to the oceans from European rivers. For this a standardized protocol for floating riverine macrolitter was developed (González-Fernández \& Hanke, 2017). Volunteers acquire data by visually counting litter particles floating by for approximately 30 minutes per session, and sessions were repeated throughout a period of one year (September 2016 - September 2017). With this method the RIMMEL project has been able to gather first order-of-magnitude estimates of floating litter exports for over 30 locations in Europe. Moreover, data gathered through the RIMMEL project allowed for the determination of most frequently found items in European river systems, which include plastic fragments, bottles, bags, and food packaging among others (González-Fernández \& Hanke, 2018). This information can then be used to implement highly focused policy with the aim to reduce the presence of these litter items. RIMMEL is a very relevant reference project for a national litter monitoring strategy since it is an example of a fully developed method which can be directly applied.

Table 1: Overview of most frequently found litter items found in European rivers, adapted from González-Fernández \& Hanke, 2018)

\begin{tabular}{|c|c|c|c|c|}
\hline Ranking & Item & Material & MSFD Code & $\%$ of Total Items \\
\hline 1 & Plastic pieces $2.5 \mathrm{~cm}><50 \mathrm{~cm},>50 \mathrm{~cm}$ & Plastic & $G 79+G 80$ & $38.59 \%$ \\
\hline 2 & Bottles & Plastic & G6 & $9.55 \%$ \\
\hline 3 & Cover / packaging & Plastic & G38 & $8.42 \%$ \\
\hline 4 & Bags & Plastic & G2 & $7.77 \%$ \\
\hline 5 & Polystyrene pieces $2.5 \mathrm{~cm}\rangle\langle 50 \mathrm{~cm},>50 \mathrm{~cm}$ & Plastic & $G 82+G 83$ & $6.35 \%$ \\
\hline 6 & Other paper items & Paper/Cardboard & G158 & $4.01 \%$ \\
\hline 7 & Paper packaging & Paper/Cardboard & G149 & $3.61 \%$ \\
\hline 8 & Sheets, industrial packaging, plastic sheeting & Plastic & G67 & $2.93 \%$ \\
\hline 9 & Foam packaging/insulation/polyurethane & Plastic & G74 & $2.70 \%$ \\
\hline 10 & Cans (beverage) & Metal & G175 & $2.05 \%$ \\
\hline 11 & Other plastic/polystyrene items (identifiable) & Plastic & G124 & $1.98 \%$ \\
\hline 12 & Crates and containers / baskets & Plastic & G18 & $1.81 \%$ \\
\hline 13 & Other (metal) & Metal & G197 & $1.48 \%$ \\
\hline 14 & Newspapers \& magazines & Paper/Cardboard & G154 & $1.19 \%$ \\
\hline 15 & Beams / Dunnage & Processed wood & G169 & $0.99 \%$ \\
\hline 16 & Other rubber pieces & Rubber & G134 & $0.95 \%$ \\
\hline 17 & Wood boards & Processed wood & G168 & $0.72 \%$ \\
\hline 18 & Synthetic rope & Plastic & G48 & $0.71 \%$ \\
\hline 19 & Other textiles (incl. rags) & Cloth/textile & G145 & $0.57 \%$ \\
\hline 20 & Pallets & Processed wood & $\mathrm{G} 160$ & $0.48 \%$ \\
\hline
\end{tabular}

\subsubsection{Plastic Pirates, Germany}

The Plastic Pirates project is based on the premise to train schoolchildren to quantify floating and riverbank litter. For this, Kiessling et al. (2019) have developed an elaborate program to be taught in schools (Plastic Pirates, n.d.). The teaching materials include classes to be taught to the children on the effects of litter on 
the environment, how to gather field data, and the program ends with a day where all participating school characterize litter at a designated riverbank. The sampling method used by Kiessling et al. (2019) is based on the method developed by Rech et al. (2015). Using this method, a total of 250 sampling locations along German rivers were analysed during both autumn 2016 and spring 2017 (Figure 13, Kiessling et al., 2019). The analysis has continued biannually since this period, but these results have not yet been published. Important findings by the Plastic Pirates project include a first estimation of litter densities on German riverbanks (0.54-1.20 litter items per $\mathrm{m}^{2}$ ) and insights in riverine litter composition (Kiessling et al., 2019). Key characteristics of the Plastic Pirates project that could be interesting to a Dutch national litter monitoring project are the way in which the project works together with the German government, a welldeveloped method that could be applied on Dutch riverbanks, and the added educational value such a program can bring to younger generations.

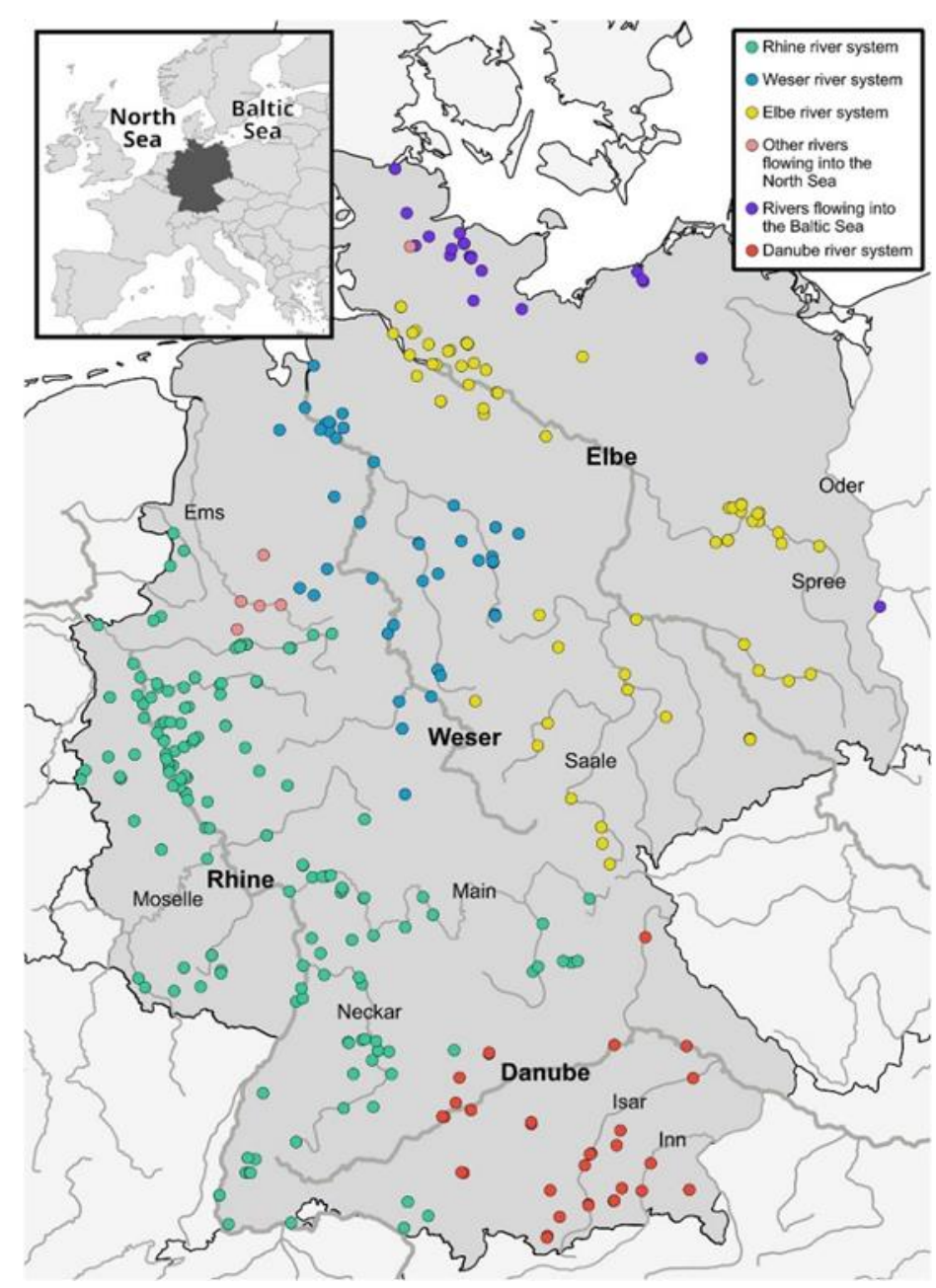

Figure 13: Overview of locations $(n=250)$ sampled during the Plastic Pirates project, adapted from Kiessling et al. (2019).

\subsubsection{Emissions of the Ems, Weser and Elbe, Germany}

Schöneich-Argent et al. (2020) is one of the first studies that has tried to quantify macroplastic transport in all five river compartments (e.g. river surface, water column, river bed, riverbank) as identified by van Emmerik \& Schwarz (2020). The researchers from the university of Oldenburg did this by combining existing methods such river-OSPAR method for riverbank litter and the RIMMEL approach for floating macrolitter. This methodology was applied for approximately half a year to three rivers in Germany: the lower Ems, Elbe, and Weser. By doing so, Schöneich-Argent et al. (2020) were able to estimate total macrolitter exports from each river, which range from $0.9-801$ metric tonnes of plastic per year, as well as determine the relative share of each river compartment to the total transport of litter. 
This study can be an important reference project since it is the first study to apply methods to quantify plastic in all river compartments. A national monitoring strategy in the Netherlands should strive towards such integrated approach as well. Methods used by Schöneich-Argent et al. (2020) include tow nets for litter in the water column, bottom trawls for riverbed litter transport, and visual observations for floating litter transport (Figure 14), which can all also be applied in Dutch rivers. Studying these methods or collaborating with the authors could therefore save time and effort with developing a monitoring strategy for the Netherlands.

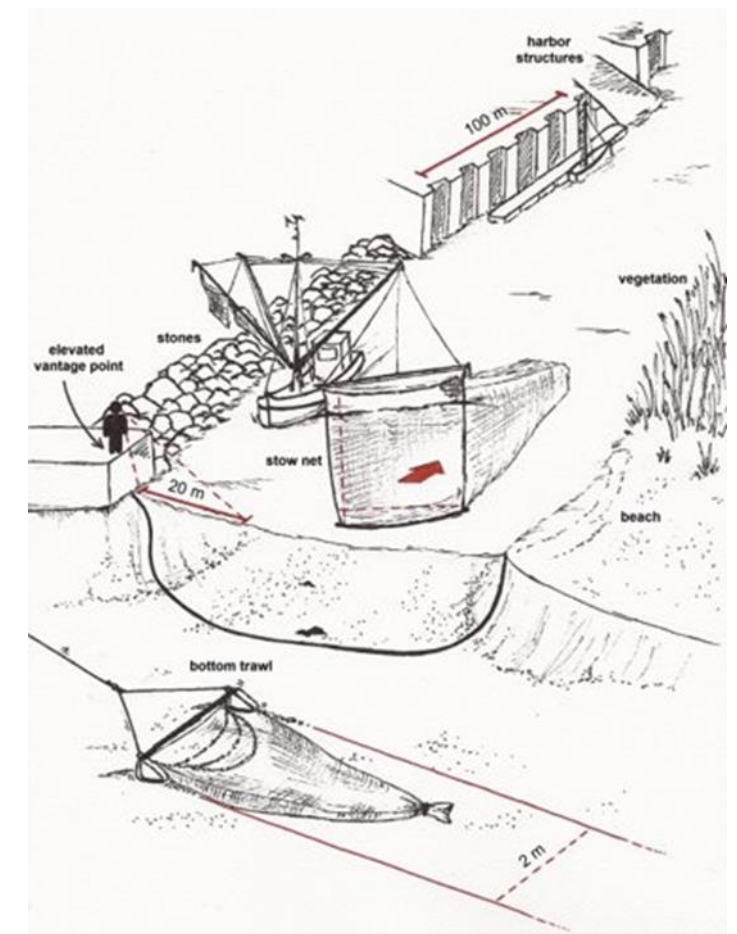

Figure 14: Overview of methods deployed by Schöneich-Argent et al. (2020) to quantify riverine litter transports and accumulation on riverbanks.

\subsubsection{National Baseline, Indonesia}

The Indonesian Institute of Sciences has recently published on their efforts to set a baseline estimate of plastic debris in the Indonesian marine environment (Nurhati \& Cordova, 2020). To gather this baseline, they have adopted the approach to perform a meta-analysis of previously published studies and used their findings to recommend a monitoring strategy for the coming years. This meta-analysis included four plastic export models and studies on 18 beaches across Indonesia. Their main findings include an estimated input of 0.5 million metric tonnes of plastic per year into the oceans, and an average accumulation rate of 113.6 $\mathrm{g}$ per $\mathrm{m}^{2}$ of beach per month. The Indonesian baseline study is an interesting reference project since it is based on previously gathered data which is combined to gain an understanding of plastic pollution on a national scale. Dutch rivers have also been previously studied by different parties. Combining these different data sources could give new insights, and aid with the development pf a national monitoring strategy.

\subsubsection{Echo sounding for underwater litter monitoring, Netherlands and Spain}

Technologies to monitor sub-surface litter are not very developed yet. A promising technique is to detect litter items in the water column using echo sounding. Echo sounding is widely used to locate fish by fishermen and to gather data on the bathymetry of lakes and oceans. Broere (2020) has shared a proof of concept that the sonar-based technology can also be used to detect macroplastic items suspended in the water column, though further development is needed before echo sounding can be applied on a large scale. Quantification of litter suspended in the water column has been proven to be difficult, this project is therefore an important reference project for the monitoring of underwater riverine litter. 


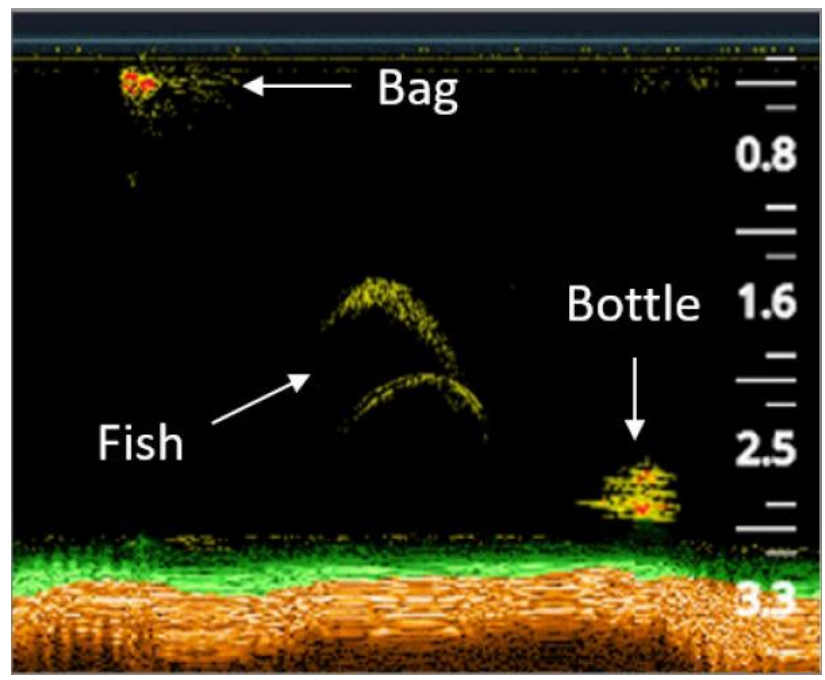

Figure 15: Example of echo sounding detection of underwater litter in the Guadelete river, Spain (Broere, 2020).

\subsection{Summary table of recent developments}

In Table 2 we present an overview of the projects and studies considered. For each entry the location, river compartment, location within the river system, time period and report units are included. As can be seen, most efforts have focused on riverbanks and floating litter.

Table 2: Summary table of recent developments concerning litter monitoring and quantification.

\begin{tabular}{|c|c|c|c|c|c|}
\hline Project & Country & $\begin{array}{l}\text { River } \\
\text { compartment }\end{array}$ & $\begin{array}{l}\text { Location in } \\
\text { river basin }\end{array}$ & $\begin{array}{l}\text { Time } \\
\text { period }\end{array}$ & Units \\
\hline Schone Rivieren & The Netherlands & Riverbank & Delta & 2 years & items/m2 \\
\hline Plastic spotter & The Netherlands & Floating & $\begin{array}{l}\text { Urban water } \\
\text { systems }\end{array}$ & one off & items/m2 \\
\hline Scouts4Science & The Netherlands & $\begin{array}{l}\text { Riverbank and } \\
\text { Floating }\end{array}$ & Delta & - & items/m2 \\
\hline $\begin{array}{l}\text { University of Applied } \\
\text { Sciences Rotterdam }\end{array}$ & The Netherlands & Riverbank & Delta & not set & items/m2 \\
\hline $\begin{array}{l}\text { University of Applied } \\
\text { Sciences Zeeland }\end{array}$ & The Netherlands & Riverbank & Delta & not set & items/m2 \\
\hline Clear Rivers & The Netherlands & $\begin{array}{l}\text { Riverbank and } \\
\text { floating }\end{array}$ & Delta & not set & $\begin{array}{l}\text { items } / \mathrm{m} 2 \text { and } \\
\mathrm{mass} / \mathrm{m} 2\end{array}$ \\
\hline Great Bubble Barrier & The Netherlands & Floating & $\begin{array}{l}\text { Urban water } \\
\text { systems }\end{array}$ & - & - \\
\hline Shoreliner & The Netherlands & Floating & Delta & - & - \\
\hline Noria & The Netherlands & Floating & Delta & - & - \\
\hline Catchy & The Netherlands & Floating & Delta & - & - \\
\hline LIVES Project & The Netherlands & $\begin{array}{l}\text { Riverbank and } \\
\text { Floating }\end{array}$ & Delta & - & - \\
\hline RIMMEL project & $\begin{array}{l}30 \text { locations } \\
\text { across Europe }\end{array}$ & Floating & River mouth & 1 year & items/hour \\
\hline Plastic Pirates Project & Germany & Riverbank & Full basin & $\begin{array}{l}\text { Since } \\
2016\end{array}$ & $\begin{array}{l}\text { items } / \mathrm{m} 2 \text { and } \\
\mathrm{mass} / \mathrm{m} 2\end{array}$ \\
\hline $\begin{array}{l}\text { Mass balance Ems, } \\
\text { Weser, and Elbe }\end{array}$ & Germany & $\begin{array}{l}\text { All } \\
\text { compartments }\end{array}$ & River mouth & $\begin{array}{l}6 \\
\text { month } \\
\text { s }\end{array}$ & $\begin{array}{l}\text { dependent on } \\
\text { compartment }\end{array}$ \\
\hline $\begin{array}{l}\text { Baseline plastic pollution } \\
\text { Indonesia }\end{array}$ & Indonesia & $\begin{array}{l}\text { Model and } \\
\text { beach (marine) }\end{array}$ & River mouth & - & mass/m2 \\
\hline Echo sounding & Spain & Column & River mouth & - & items/hour \\
\hline
\end{tabular}




\section{$4 \quad$ Giving direction - Goals for riverine litter monitoring}

The Roadmap is designed as a tool to give direction for the design of a national riverine litter monitoring strategy. For the design of the Roadmap we formulated the possible goals that can be achieved through a national monitoring strategy. Input was collected from a Rijkswaterstaat (RWS) expert panel through a survey. More details about this process are discussed in the next section. Based on the input from the survey we defined (1) goals for monitoring, (2) a timeline for sub-goals, and (3) a list of key questions.

\subsection{Expert survey}

The expert survey was conducted between 14 and 21 September, 2020. The survey consisted of twenty open and multiple choice questions. Most questions asked input on (1) the current state of the knowledge with respect to litter and litter monitoring in Dutch rivers, (2) the possible reasons for monitoring, and (3) what metrics and river components should be monitored. The complete question list can be found in Annex 1. In total 16 RWS experts participated in the survey with different expertise, working areas and affiliations. Figure 16 shows the expertise of the expert panel. Note that respondents could select multiple fields. Most experts self-identified as experts in litter and monitoring. Figure 17 presents the affiliations of the experts, and it can be seen that the majority of the experts were affiliated with WVL (Water, Verkeer en Leefomgeving - Water, Traffic and Living Environment), followed by ZD (Zee en delta - Sea and delta).

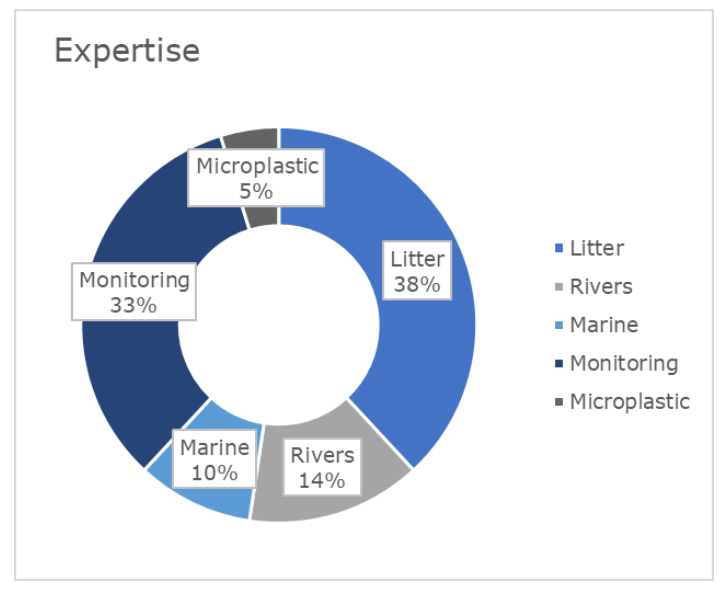

Figure 16: Overview of the (self-identified) expertise of the 16 RWS expert panel members.

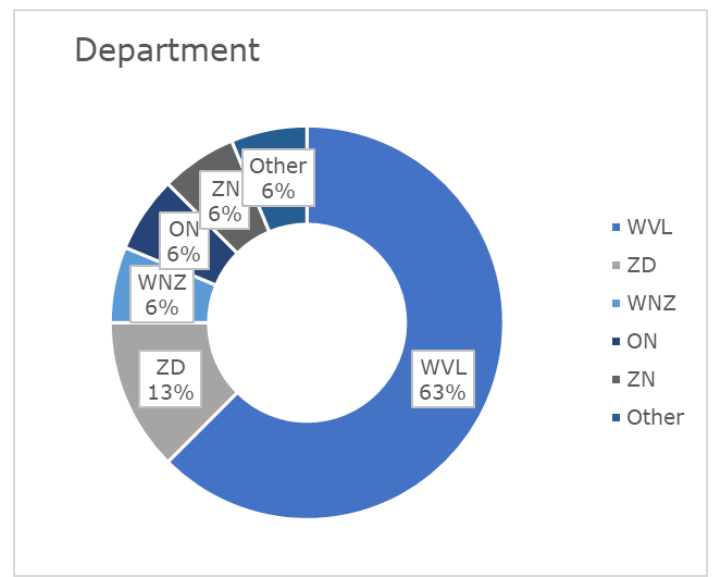

Figure 17: Overview of the affiliations of the 16 RWS expert panel members. Abbreviations: WVL Water, Verkeer en Leefomgeving; ZD - Zee en delta; WNZ - West-Nederland-Zuid; ON - OostNederland; ZN - Zuid-Nederland. 
Figure 18 indicates the working areas of the experts. Most experts self-identified as working with litter monitoring (45\%) and in the Riverine environment (35\%). Overall, the composition of the expert panel was considered relevant for providing input for the Roadmap. The experts had an overall strong expertise in the riverine environment and with litter monitoring, complemented with valuable experience from other disciplines and working fields.

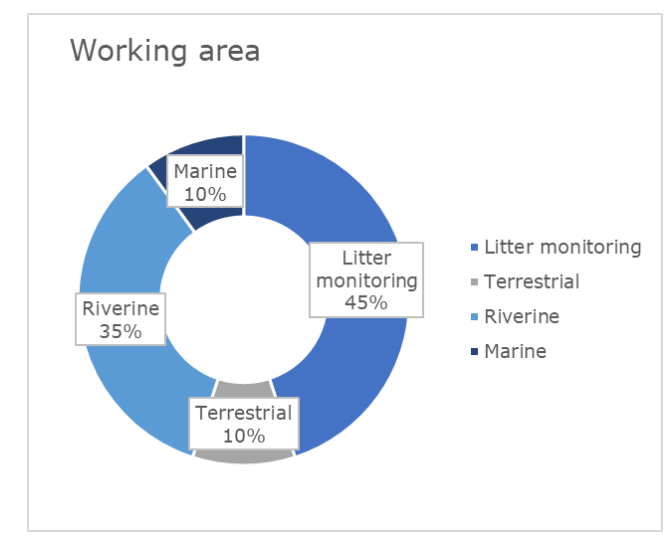

Figure 18: Overview of the (self-identified) working areas of the 16 RWS expert panel members.

\subsection{Results of the expert survey}

Figure 19 presents the reasons for monitoring, according to the expert panel. Note that experts could select multiple answers. The most important reasons for riverine litter monitoring were found to be (1) data collection, (2) decreasing litter, (3) trend analysis, and (4) source identification (all $>60 \%$ ). The least selected reason for monitoring was to deploy collection systems $(<30 \%)$.

\section{Reasons for monitoring}

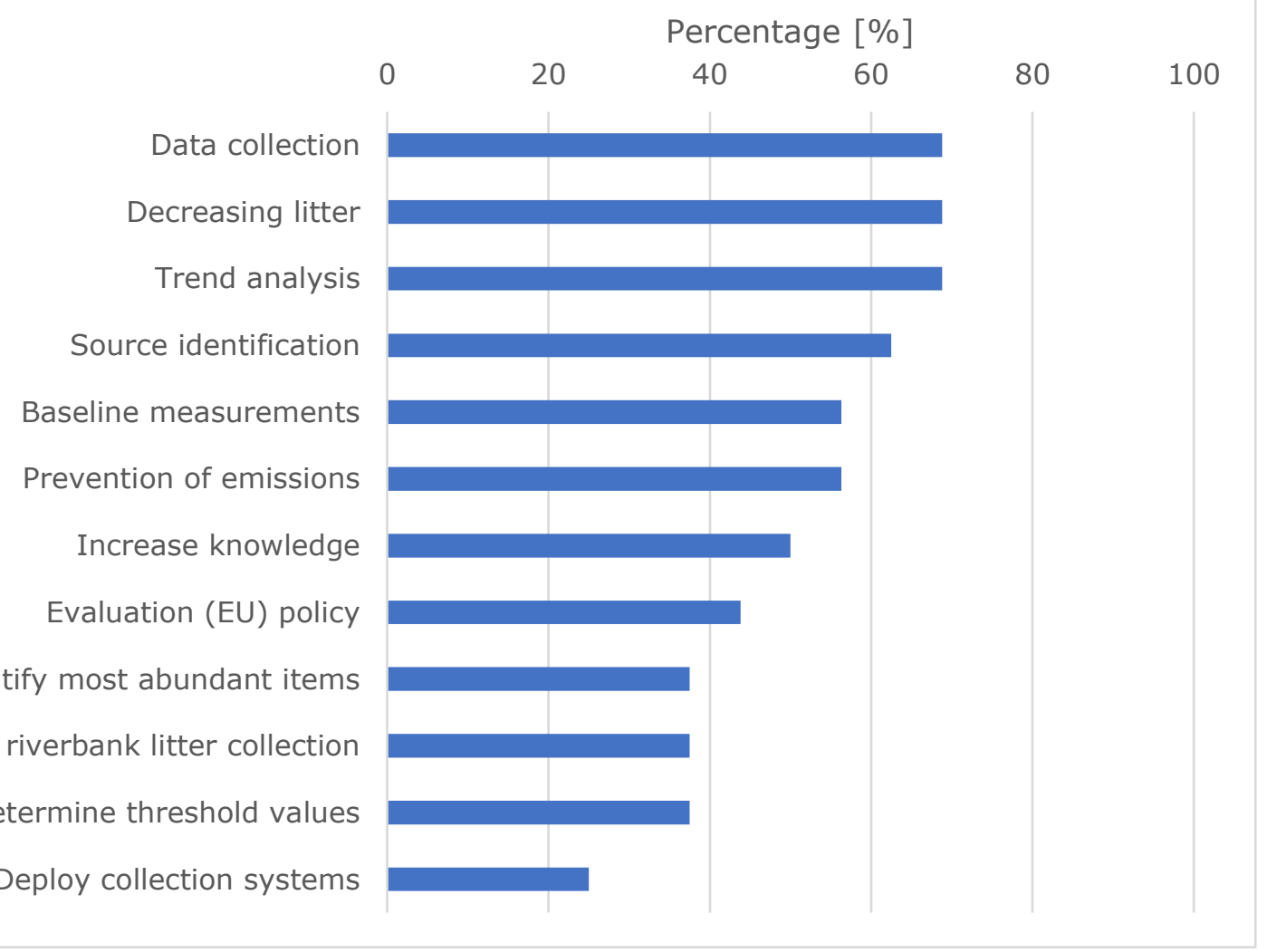

Figure 19: Reasons for riverine litter monitoring based on the input from the expert panel. Note that experts could select multiple answers. 
Figure 20 lists the indicators and variables that should be monitored according to the experts. The most important indicators selected were (1) the material type of litter (80\%), (2) the mass balance of litter in rivers $(>60 \%)$, and $(3)$ litter concentrations in rivers $(\sim 60 \%)$. The least selected indicators were the more specific indicators, such as concentrations in sediment, and density on riverbank $(<40 \%)$. Surprisingly, the transport load of litter in rivers was not considered an important indicator. However, this maybe be included in the mass balance, with as overall ranked as important.

\section{What indicators should be monitored}

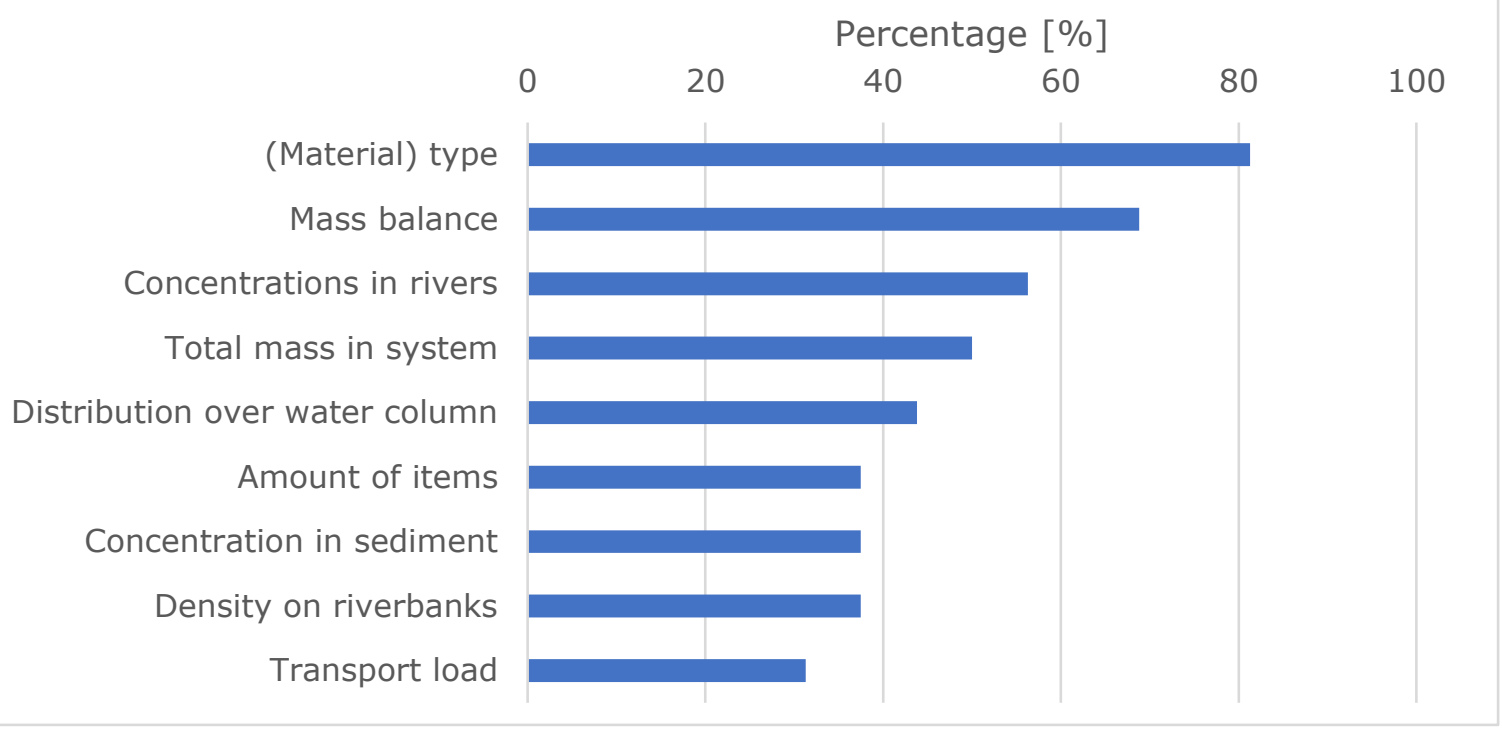

Figure 20: Reasons for riverine litter monitoring based on the input from the expert panel. Note that experts could select multiple answers.

The current knowledge level as estimated by the expert panel is shown in Figure 21. The knowledge level for riverbanks and floating litter was considered the highest, and the water column and sediment the lowest. These estimates are in line with the available studies and data on litter in these compartments in the Dutch rivers. It is surprising though that even the riverbank litter knowledge level was estimated this low (2.7 out of 5), given the Schone Rivieren project that has been collecting data at over 200 locations since 2017.

\section{Current knowledge level}

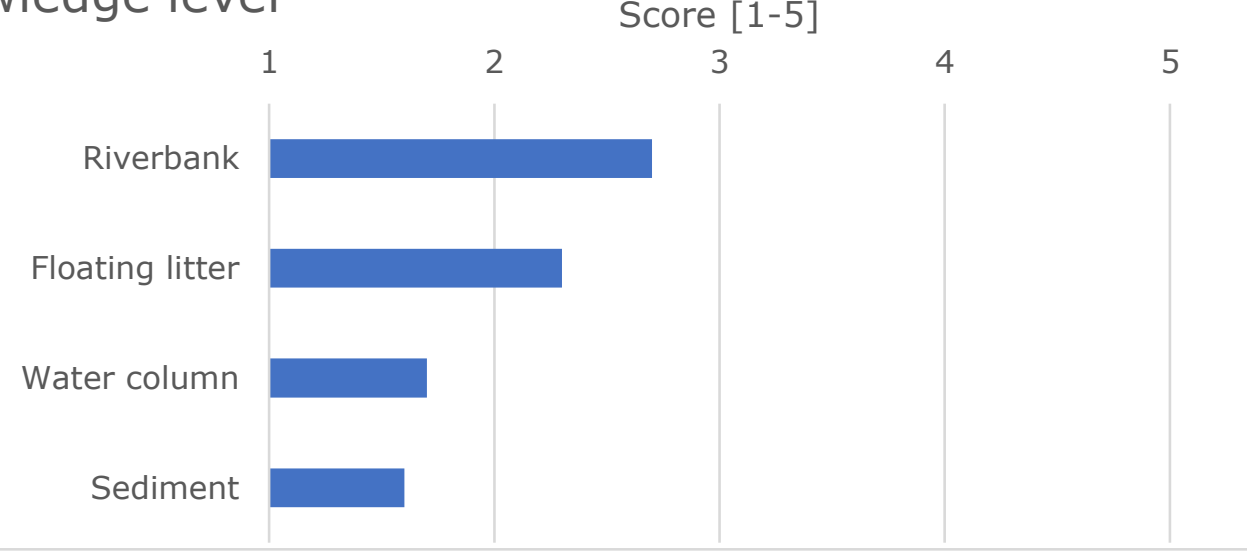

Figure 21: Reasons for riverine litter monitoring based on the input from the expert panel. Note that experts could select multiple answers. 


\subsection{Four main goals}

\section{Goal 1: Policy}

The first main goal of riverine litter monitoring is to support the development policy. There has been an increase in new guidelines and regulations related to (plastic) litter in aquatic environment, such as the Marine Strategy Framework Directive (NL: Kaderrichtlijn Mariene Strategie, KRM), the Water Framework Directive (NL: Kaderrichtlijn Water, KRM) and the Single-use Plastics Directive (NL: Single Used Plastic richtlijn, SUP). Monitoring is necessary to determine whether any threshold values are exceeded, and whether any policy goals are achieved. Furthermore, litter monitoring will support the development of item or material specific policies. Finally, as rivers are transboundary systems, policy for litter monitoring has to be done in collaboration with neighbouring regions and the other members of the Rhine and Meuse river basin committees.

\section{Goal 2: Knowledge development}

The second goal relates to all actions and activities for knowledge development. To date, the understanding of litter sources, sinks, pathways, retention times, degradation and fragmentation is limited. Such knowledge is crucial for optimizing prevention, mitigation and reduction strategies. Another crucial knowledge gap is the distribution of litter across river compartments. Most efforts to date have focused on floating litter or litter on riverbanks. It remains unclear how much litter is suspended below the surface in the water column, or is (temporarily) deposited in sediment. Better estimates of the distribution of litter in turn allows for more realistic Life Cycle Assessments (LCA) of specific products, as the actual environmental and economic risks of these products will be revealed. Finally, knowledge development will contribute to better forecasting of leakage of litter into the environment. Understanding the effect of for example storms and high river discharge on the leakage, mobilization and transport of litter through rivers can support better preventive measures.

\section{Goal 3: Operations}

Rijkswaterstaat may also consider riverine litter monitoring as an intrinsic task. As responsible stakeholder for the main waterways, hydrological, chemical, and other monitoring are already an integral of RWS' monitoring programme. In the future, riverine litter monitoring can be integrated in the Monitoring Waterstaatkundige Toestand des Lands (MWTL). Such integrated is related to the data collection, processing and dissemination. The current Waterinfo dashboard allows the public and experts to navigate through the available data and near-future forecasts. Riverine litter data can also be included in the dashboard.

\section{Goal 4: Solutions}

Finally, the riverine litter monitoring strategy will support the development, implementation and evaluation of any solution to reduce litter. Litter monitoring can provide quantitative data on the efficacy of policy changes, improved infrastructure or specific litter collection strategy. For example, to determine the efficacy of litter traps, quantitative data is required of the total amount of litter or litter load in the river system. Effects of targeted policy can also be evaluated. Long-term data allows for trend analyses that may show that discouraging or banning specific products also leads to a decrease of those products in the (aquatic) environment. Monitoring is crucial to optimize implementation of specific measures. This may include the installation of a waste collection system. Data can support the selection of the installation location along a river, and the side of the river. Furthermore the data can be used to forecast during what periods most and least litter is expected to be transport and collected.

\subsection{Short, medium and long-term goals}

One of the survey questions answer the experts to provide insights in the timeline of goals that can or should be achieved through the national riverine litter monitoring strategy. The goals were categorized in three periods: (1) short term, (2) medium term and (3) long-term. The findings are emphasized by the word cloud presented in Figure 22. 

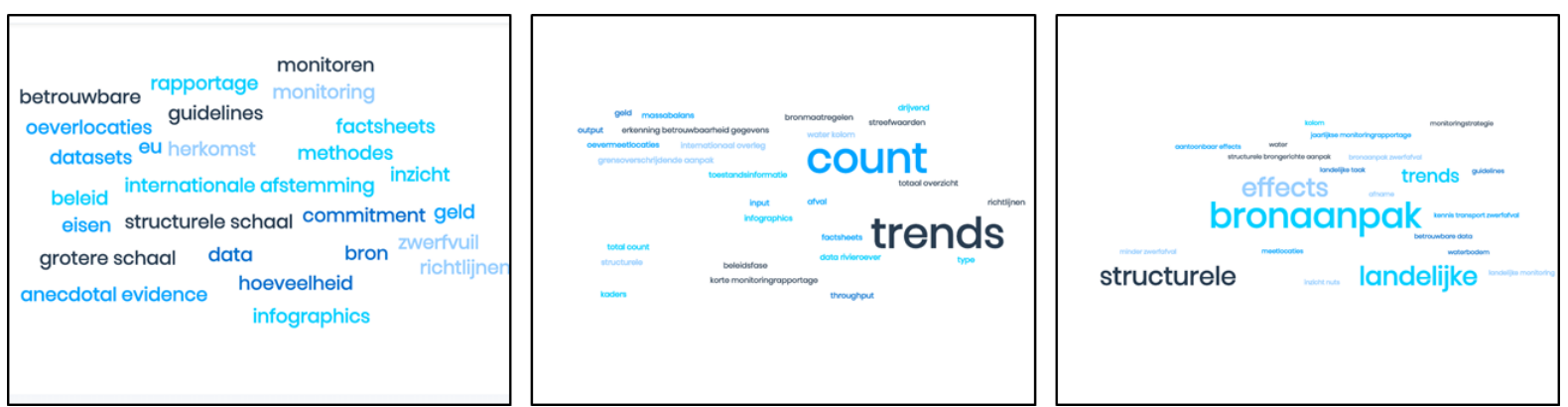

Figure 22: Word cloud of the expert input for the short term (left), medium term (middle) and long term (right). Note the input was given in Dutch and has not been translated.

\section{Short term (1-3 years)}

The left panel in Figure 22 shows the cluster of words from the expert response related to the short term goals. Short term goals are related to data, monitoring, methods, sources, financial commitment, and norms. The word cloud highlights the myriad of angles that should be considered. The development of the national monitoring strategy would benefit from an open discussion with various stakeholders, to include these different perspectives.

\section{Medium term (3-5 years)}

For the medium term goals, the expert responses show more agreement. Although still several goals are mentioned, the two clear goals that stand out are trends and counts. This can be interpreted as a strong need for data collection, and the capacity development for trend analysis. Stakeholders and policymakers are motivated to evaluate the efficacy of measures, and for that baseline values and long-term observations are crucial. On the medium term, the national monitoring strategy should focus on starting data collection, even though the methods and protocol may be still subject to review.

\section{Long term ( $>5$ years)}

The long-term goals reflect the convergence of priorities. Clear goals include the need for structural and national approaches, measures at the sources of litter, and quantifying trends and effects of measures. From the findings and experience on the medium term, long-term data collection protocols should be developed and implemented. The expert input demonstrates a realistic order of priorities and possibilities. Reliable trend analyses would be beneficial for many stakeholders, but first long-term data collection is required as input for such analyses. 


\subsection{The open questions}

As a result of the expert survey, we defined fifteen open questions that need to be answered through the national monitoring strategy, see Table 3. These questions will be the backbone of the Roadmap, as it demonstrates the priority, urgency and timeline of the next steps for the national monitoring strategy.

Table 3: Overview of the open questions.

\begin{tabular}{|c|c|}
\hline No. & Question \\
\hline 1 & How can litter be monitored in each river compartment? \\
\hline 2 & How to determine the litter mass balance for Dutch rivers? \\
\hline 3 & What is the emission of litter from rivers into the ocean? \\
\hline 4 & How to determine litter hotspots in time and space? \\
\hline 5 & What are the sources of riverine litter? \\
\hline 6 & How to measure the impact of measures? \\
\hline 7 & What are appropriate norm and target values for riverine litter? \\
\hline 8 & What are the litter transport pathways through Dutch rivers? \\
\hline 9 & What is the most abundant litter material type? \\
\hline 10 & How is litter distributed over the river compartments? \\
\hline 11 & $\begin{array}{l}\text { How can riverine litter monitoring be integrated in the overall RWS } \\
\text { monitoring program? }\end{array}$ \\
\hline 12 & $\begin{array}{l}\text { How can riverine litter monitoring be streamlined with neighboring } \\
\text { regions? }\end{array}$ \\
\hline 13 & $\begin{array}{l}\text { How to collaborate with stakeholders across scales (local to } \\
\text { international)? }\end{array}$ \\
\hline 14 & What is the role of citizen science in riverine litter monitoring? \\
\hline 15 & How to standardize measurement units? \\
\hline
\end{tabular}




\section{$5 \quad$ Roadmap for a national riverine litter monitoring strategy}

In this chapter we present the Roadmap for riverine litter monitoring. Before presenting the Roadmap, we explain the rationale and build-up of the roadmap. The Roadmap offers a framework with clear structure and flexibility. First, these two pillars are explained in more detail.

\section{$5.1 \quad$ Structuring questions}

The fifteen open questions have been structured using a three-level framework. In the end, each question is related to data, though at a different level. In the Roadmap, we distinguish three specific levels: (1) monitoring methods, (2) the baseline, and (3) long-term monitoring. The first level (monitoring methods) relates to all technical and methodological developments that are the foundation of suitable monitoring strategy. For example, to monitor plastics in the water column no standard method is available. The first step to solving this question therefore starts at level one. The second level (baseline) focuses on doing a quick scan of litter in a specific compartment. Quick scans are crucial to determine appropriate norm and target values, and for choosing the final long-term monitoring protocol. As shown by van Calcar \& van Emmerik (2019), floating litter flux can vary more than five orders of magnitude around the world. A quick scan will reveal the approximate local of the considered river within that space. More or less polluted rivers may require a specific monitoring strategy. Finally, the third level relates to the actual long-term monitoring strategy. At this level, questions about trends and effects of policy changes can be answered. This is not possible at one of the lower levels.

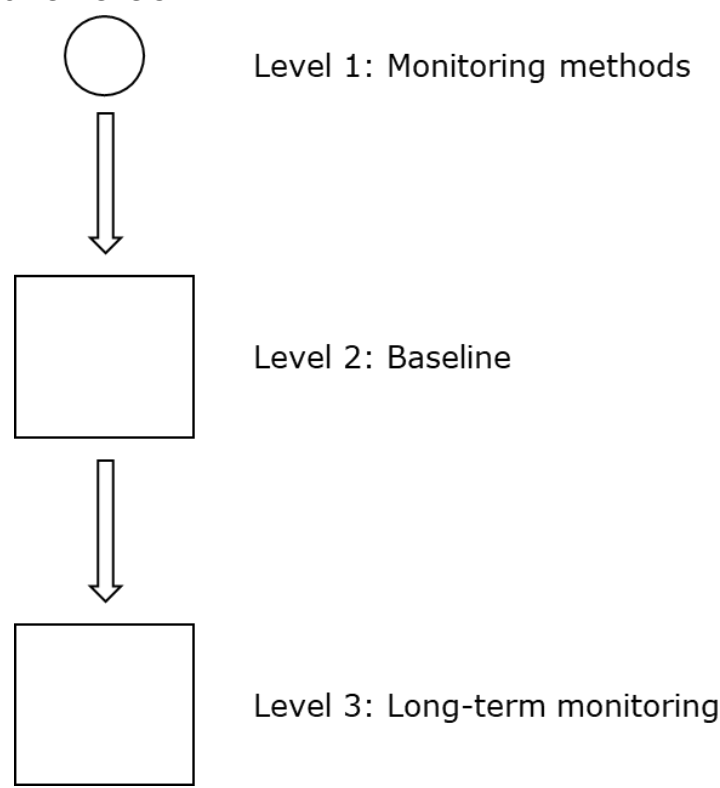

Figure 23: Framework for structuring the research questions.

\subsection{Adding flexibility}

The proposed three-level structure can be used to assess the current and desired state of knowledge and monitoring for specific compartments. For example, the current monitoring strategy for riverine litter only includes riverbank litter through the Schone Rivieren project. On the first level (monitoring methods), an working solution has been found to how to measure riverbank litter. The Schone Rivieren project optimized their self-developed River-OSPAR method to quantify and characterize litter at over 200 locations along the Dutch rivers through citizen science. The first measurement rounds (2017-2018) provided a clear baseline for riverbank litter along Dutch rivers (second level). These baseline values provided the first statistics on the abundance of riverbank litter, the spatial distribution and the item types. However, only after the continuation of the monitoring ever since, the data allows for trend analysis, and observed variations can be attributed to policy change with a high degree of confidence. Depending of the level of the questions that should be answered, the framework shows at what level $(1,2$ or 3$)$ the strategy should focus. If this does not match with the current available data or monitoring strategy, it also shows the steps 
needed to arrive at the desired level. If the goal is to do trend analysis, levels 1 and 2 should already be unlocked. If not, these steps should be taken first.

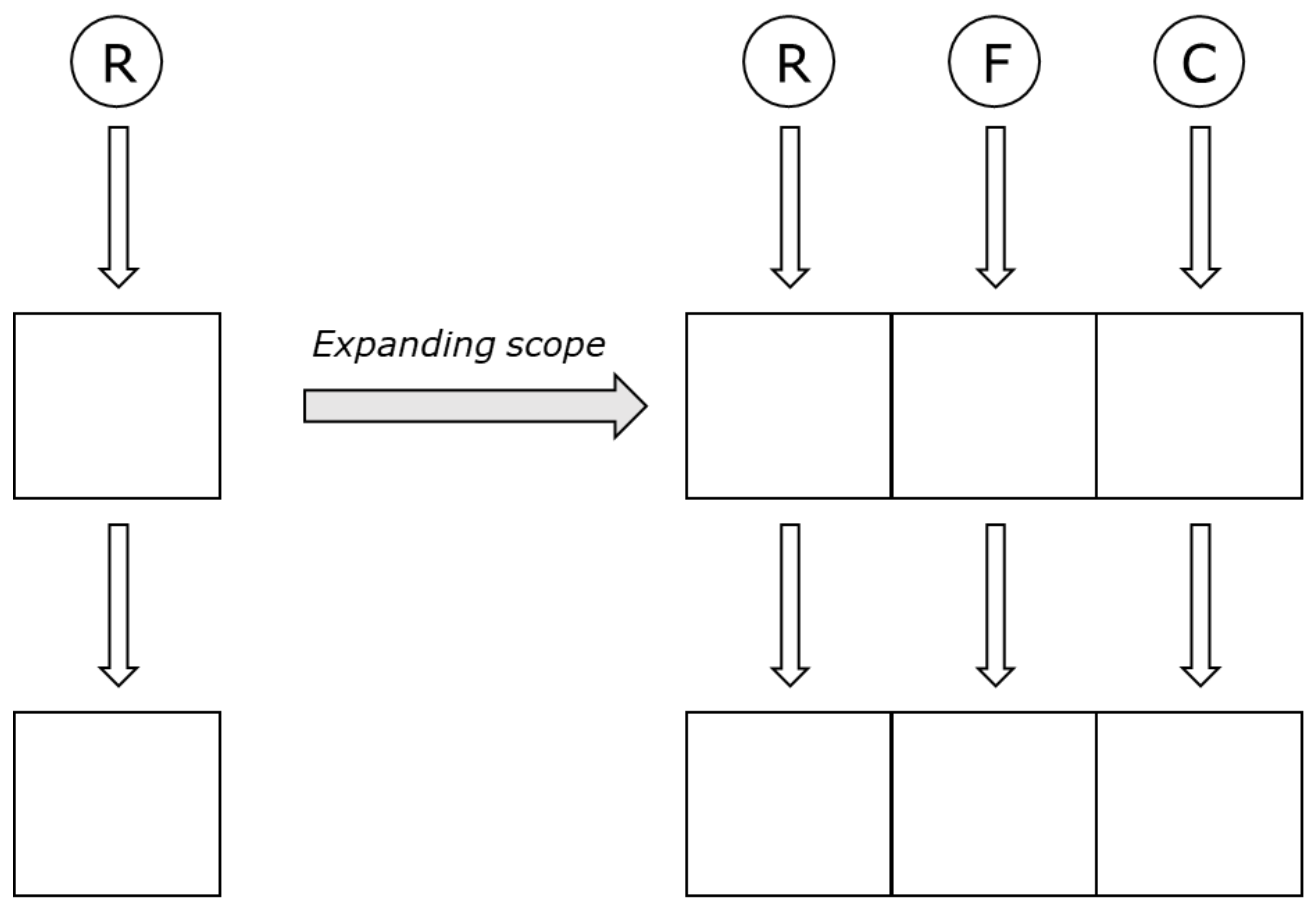

\section{R: Riverbank - F: Floating - C: Water column - S: Sediment - B: Biota}

Figure 24: Application of the framework to a single and multiple river compartment(s).

The framework is flexible in two directions. As discussed, the stepwise approach facilitates extension of the current or future monitoring campaign. One levels 1 and 2 are checked, the strategy can be extended with the next level. The framework also shows how to expand the scope of the strategy. To date, the Dutch strategy only includes long-term monitoring for riverbank litter. By also considering other river compartments, such as floating and water column, the framework is expanded. Figure 24 shows the result of expanding and extending a strategy. At level 1 (monitoring methods), each compartment requires specific technology and protocols (for example visual counting for floating litter, and net sampling for water column litter). At the second level (Baseline), the compartments form an integrated strategy to allow for an holistic approach for the monitoring protocols, data collection, analysis and dissemination. Also on the third level (long-term monitoring) the compartments remain connected and integrated. The framework allows for a flexible and iterative approach, as individual components can be added, removed, or changed. For example, if a new technology for water column measurements is available, a new "column" can be added to the framework. However, here one starts again at level one, as the measurement method needs to be developed. Another possibility is to add or remove complete river compartments, based on new findings. For example, observations may show that litter in sediments is not relevant comparted to the riverbanks and floating litter. As a consequence, the sediment "column" can be removed from the strategy. Similarly, new columns (biota, floodplains, etc.) can be added through the expansion of the scope.

\subsection{The Roadmap for riverine litter monitoring in Dutch rivers}

The complete Roadmap for riverine litter monitoring in Dutch rivers is presented in Figure 24. The Roadmap includes the four main river compartments (riverbank, floating litter, sediment, water column) and an optional fifth compartment (biota). For each compartment, the three levels are included. For each level, it is indicated what questions can be answered if this level is completed for a compartment. 
After the first level, methodological questions can be answers. This includes the harmonization of units and metrics, protocols and guidelines for measurement litter in specific compartments, and methods related to modeling and statistics, such as the litter mass balance and emissions into the ocean.

After the second level, baseline data for the considered river compartments are available. This will allow for a first assessment of the distribution of litter across the river compartments. Other questions that can be answered include the sources of litter, and most abundant items and material types. Based on the first quantitative estimate of litter abundance, suitable norm and target values can also be defined.

The third level (long-term monitoring), questions related to long-term data can be answered. These include examining the effect of measures (policy, collection, or otherwise), transport pathways, and trend analyses. Also, at this level collaboration at local to international levels can be integrated in the long-term strategy. Once this level is reached, the national monitoring strategy can be integrated with the other RWS monitoring programmes focus on the riverine and marine environment.

The Roadmap can be read in two directions, either starting with the strategy or with the questions. In the previous paragraphs, we explained what questions can be answered if the strategy has reached a certain level. Alternatively, the Roadmap can also be read starting at a specific question. The Roadmap then shows what level of monitoring is required to answer that question. For example, if the strategy should answer a question related to the effect of measures, it is evident that the monitoring strategy should have reached level 3, at least for the specific compartment(s) of interest. If this is not the case, the roadmap shows what steps are necessary to arrive there. Similarly, one can also evaluate whether the monitoring strategy has elements that can be omitted. For example, of no questions are related to litter in sediments, but is part of the strategy, one may consider omitted this element.

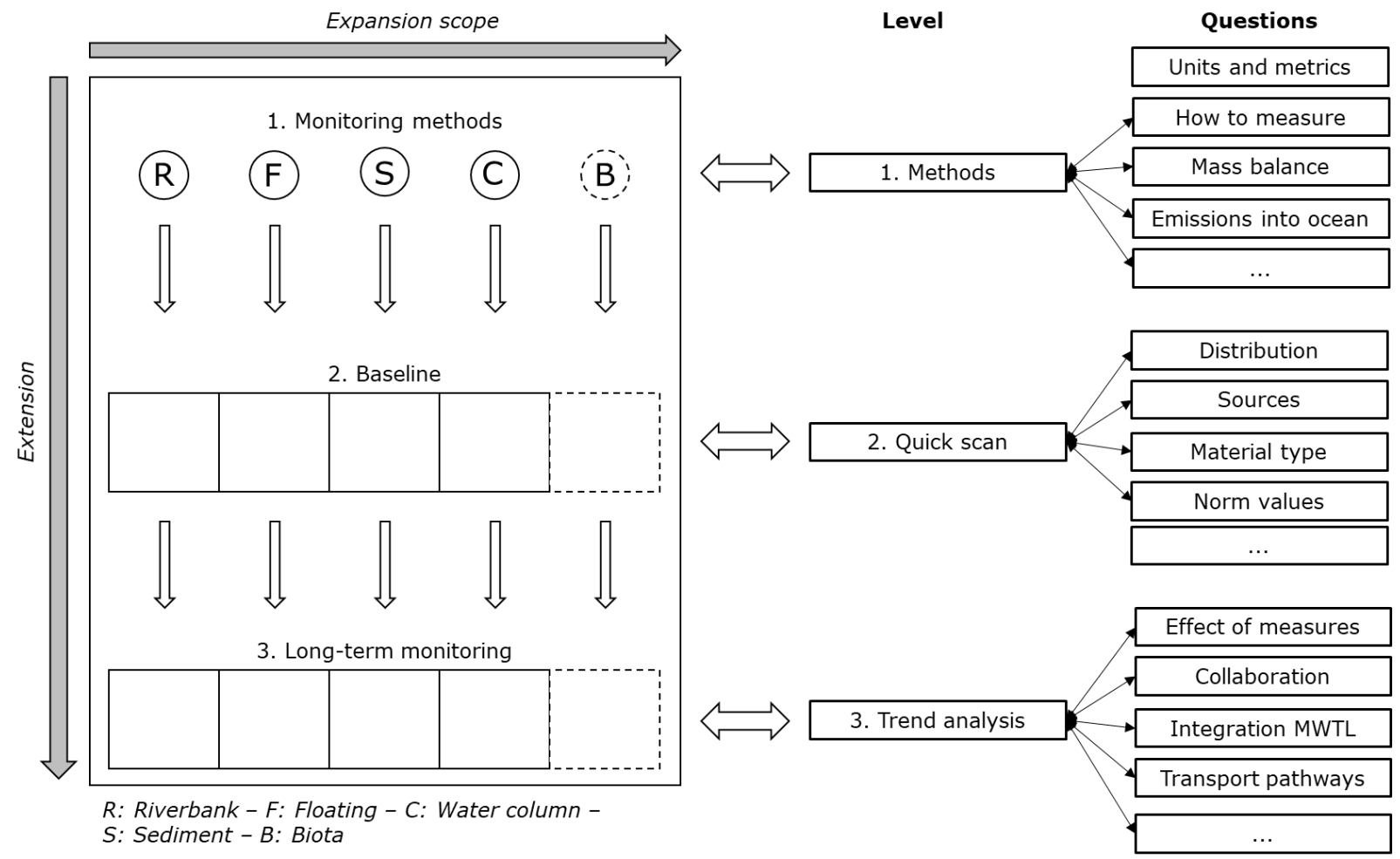

Figure 25: The Roadmap for a National Riverine Litter monitoring strategy. The Roadmap can be read in two ways. First, one can see what questions can be answered by unlocked a specific level. Second, one can start at the question to be answered, and then see what level is required in the monitoring strategy. 


\subsection{The Roadmap as dashboard}

An additional feature of the Roadmap is that it can be used as a dashboard to give insight in the current state of the litter monitoring strategy. Using three color codes, the dashboard shows what elements are achieved (green), in progress (yellow) or locked (red). The colors apply to both the elements in the elements of the monitoring strategy, and the open questions. Based on our experience, we filled out the dashboard to reflect the current situation in the Netherlands. We will briefly discuss the rationale for the selected colors.

At level one, only methods are available for riverbank and floating litter monitoring, such as visual observations, the River-OSPAR method, and drones. For sediment and water column, method development is in progress, but has not been demonstrated to work in the Dutch rivers to date. For biota, no methods are available. This has implications for the questions related to level one. For some compartments, the questions related to units and metrics, and how to measure are partially answered. However to date no efforts have been made to develop a method to determine the mass balance or emissions into the ocean.

At the second level, only a baseline is available for riverbank litter through the Schone Rivieren project. Some measurements have been made for floating litter in Dutch rivers, but more work is required to arrive at a baseline for floating litter. Based on the available data, the questions regarding sources and material type can be answered partially, but only for litter found on riverbanks.

At the third level, only the riverbank plastic is being monitored for the long term. The Schone Rivieren project has been monitoring riverbanks since 2017, and is still continuing. The available data do not suffice yet to do confident trend analyses or evaluate the effects of measures.

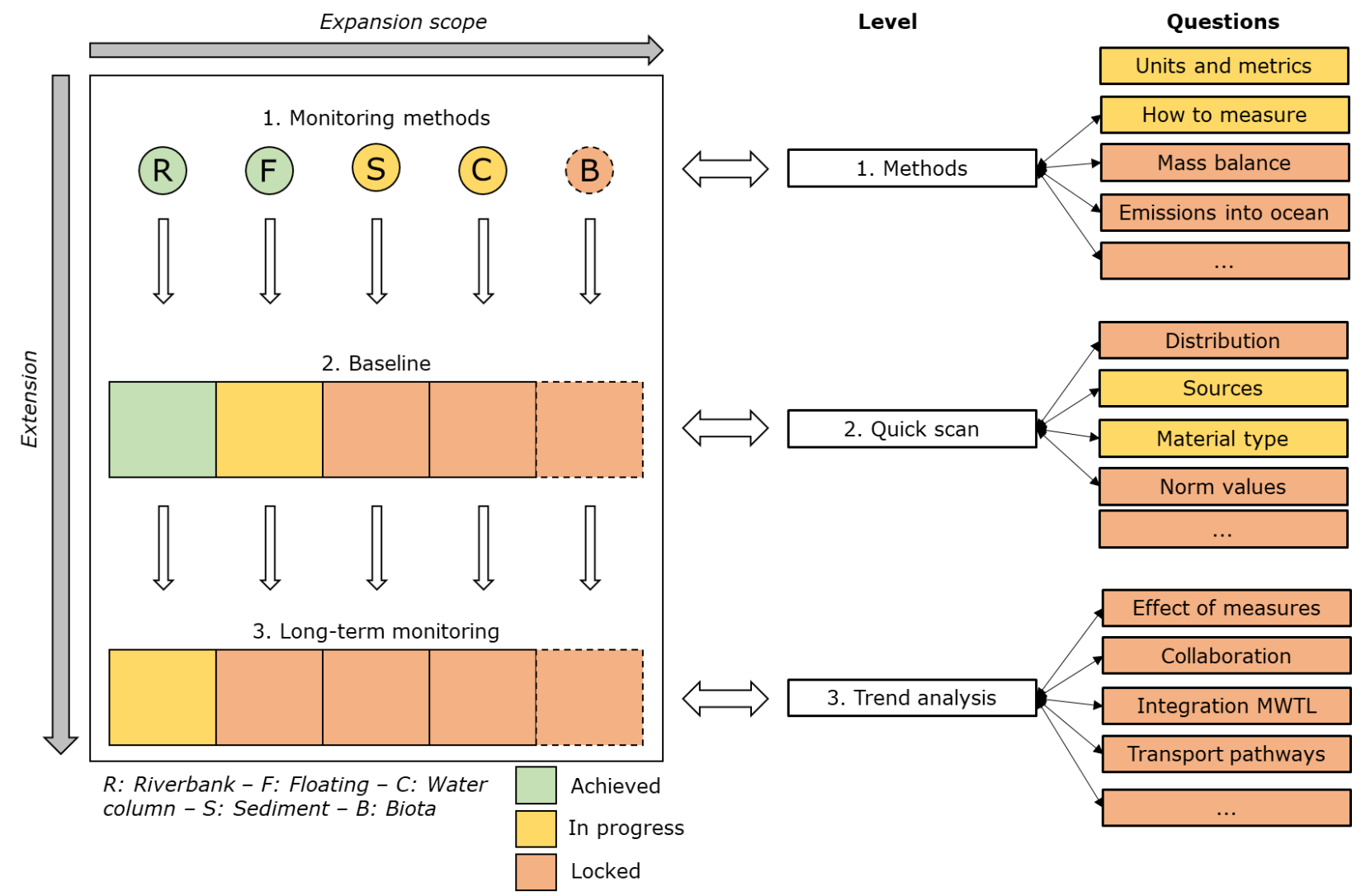

Figure 26: Example of the Roadmap as a dashboard. This version reflects the opinion of the authors with respect to the current state of the riverine litter strategy for Dutch rivers. 
Based on the Roadmap and the open questions, we formulated 24 specific project proposals that will contribute to the national monitoring strategy. We also present a simple framework to prioritize the projects. Note that the list of project proposals is not exhaustive. Projects can be removed or added, based on new findings, experiences and available resources. As several projects are similar in spirit or have substantial overlap, we have clustered the projects in six project clusters. Based on the prioritization, we suggest a timeline for planning and executing the project clusters. In the coming sections, the project proposals, prioritization, clustering and timeline will be discussed in more detail. A complete and more detailed overview of the specific projects can be found in the Supplementary Material A.

\subsection{Project proposals}

Based on the Roadmap and the list of open questions, we propose 24 specific projects that will contribute to the national monitoring strategy. The projects are listed in Table 4. For each project we include several relevant aspects. Each project indicates the focus level, ranging from 1 (monitoring methods) to 3 (longterm monitoring), see Figure 25. As some projects cannot be started without the completion of a previous project, it is indicated on what previous projects they build on. For example, for a baseline study on floating litter in Dutch rivers, the project on optimizing the floating litter monitoring method should be completed first. For each project it is also indicated to which of the four main goals they contribute, i.e. policy, operational, knowledge or solutions. This gives additional insights in what projects need to be done to achieve a certain goal. To achieve a solution-focused goal such as trend analysis riverine litter, it becomes clear that first projects 12-15 (long-term monitoring) should be done, which can only be one once projects 5-7 are completed. In turn, projects 1-4 need to be done. The Roadmap and the project overview hence provide guidance on what needs to be done to achieve specific goals, and supports the planning of the required timeline.

Table 4: Overview of the 24 project proposals to contribute to the national riverine litter monitoring strategy.

\begin{tabular}{|c|c|c|c|c|c|c|c|c|c|c|c|}
\hline & Project proposals & Level & $\begin{array}{c}\text { Build on } \\
\text { project(s): }\end{array}$ & Policy & Operational & Knowledge & Solutions & Urgent & Important & $\begin{array}{l}\text { Time/ } \\
\text { resources }\end{array}$ & Impact \\
\hline 1 & Measurement method water column & 1 & & & $x$ & $\mathrm{x}$ & & 4 & 4 & 3 & 4 \\
\hline 2 & Measurement method sediment & 1 & & & $x$ & $x$ & & 3 & 3 & 4 & 3 \\
\hline 3 & Optimize method riverbanks & 1 & & & $\mathrm{x}$ & $\mathrm{x}$ & & 4 & 5 & 2 & 3 \\
\hline 4 & Optimize method floating litter & 1 & & & $\mathrm{x}$ & $x$ & & 5 & 5 & 1 & 4 \\
\hline 5 & Baseline floating litter & 2 & 4 & $x$ & $\mathrm{x}$ & $\mathrm{x}$ & & 5 & 5 & 2 & 5 \\
\hline 6 & Baseline water column & 2 & 1 & $x$ & $x$ & $x$ & & 4 & 4 & 4 & 4 \\
\hline 7 & Baseline sediment & 2 & 2 & $x$ & $x$ & $x$ & & 3 & 3 & 5 & 3 \\
\hline 8 & Determine standard units and metrics & 1 & $1,2,3,4$ & $x$ & $x$ & & & 5 & 5 & 1 & 4 \\
\hline 9 & Develop method mass balance & 1 & & & $\mathrm{x}$ & $\mathrm{x}$ & & 4 & 4 & 2 & 4 \\
\hline 10 & Develop method emissions into ocean & 1 & 9 & & $\mathrm{x}$ & $\mathrm{x}$ & & 3 & 4 & 3 & 4 \\
\hline 11 & Determine most abundant item/material type & 2 & $5,6,7$ & $x$ & $\mathrm{x}$ & $\mathrm{x}$ & $x$ & 4 & 3 & 4 & 4 \\
\hline 12 & Long-term monitoring floating litter & 3 & $5,6,7$ & $x$ & $\mathrm{x}$ & & & 2 & 4 & 5 & 5 \\
\hline 13 & Long-term monitoring water column & 3 & $5,6,7$ & $\mathrm{x}$ & $\mathrm{x}$ & & & 2 & 3 & 5 & 3 \\
\hline 14 & Long-term monitoring sediment & 3 & $5,6,7$ & $\mathrm{x}$ & $\mathrm{x}$ & & & 1 & 2 & 5 & 2 \\
\hline 15 & Integrated long-term monitoring & 3 & $12,13,14$ & $\mathrm{x}$ & $x$ & & & 1 & 5 & 5 & 5 \\
\hline 16 & Harmonization with neighboring regions & 3 & $\begin{array}{c}15 \\
12,13,14\end{array}$ & $\mathrm{x}$ & $\mathrm{x}$ & & & 1 & 4 & 4 & 4 \\
\hline 17 & Trend analysis riverine litter & 3 & 15 & $x$ & & $\mathrm{x}$ & $x$ & 2 & 4 & 5 & 4 \\
\hline 18 & Quantify effect measures & 3 & 17 & $\mathrm{x}$ & & & $\mathrm{x}$ & 3 & 5 & 5 & 5 \\
\hline 19 & Determine norm and target values & 2 & $5,6,7$ & $\mathrm{x}$ & $x$ & & $\mathrm{x}$ & 4 & 5 & 2 & 5 \\
\hline 20 & Determine mass balance & 2 & $\begin{array}{l}5,6,7,9 \\
5,6,7,10\end{array}$ & $\mathrm{x}$ & & $\mathrm{x}$ & & 3 & 4 & 4 & 4 \\
\hline 21 & Determine emissions into the oceans & 2 & 20 & $\mathrm{x}$ & & $\mathrm{x}$ & & 4 & 4 & 4 & 4 \\
\hline 22 & $\begin{array}{l}\text { Determine sources riverine litter } \\
\text { Investigate the role of citizen science in long- }\end{array}$ & 2 & $5,6,7$ & $\mathrm{x}$ & & $\mathrm{x}$ & $x$ & 3 & 4 & 3 & 4 \\
\hline 23 & $\begin{array}{l}\text { term monitoring strategy } \\
\text { Investigate the role of alternative data sources }\end{array}$ & 1 & & $x$ & $x$ & & & 3 & 4 & 3 & 3 \\
\hline 24 & in long-term monitoring strategy & 1 & & $\mathrm{x}$ & $\mathrm{x}$ & & & 3 & 4 & 3 & 3 \\
\hline
\end{tabular}




\subsection{Prioritizing projects}

Many projects are required to arrive at an integrated long-term monitoring strategy that covers all river compartments. Available time and resources are limited, and we therefore provide a tool to prioritize the projects. We distinguish two sets of axes that are considered for each project. First, we determine the importance and urgency of each project. Second, we determine the impact and required time/resources for completion. Each of the 24 project proposals is score according to the authors' experience and the literature, yielding the combined scores presented in Figure 27. Note that these scores are subjective, and can be changed based on new insights, data, and set goals.
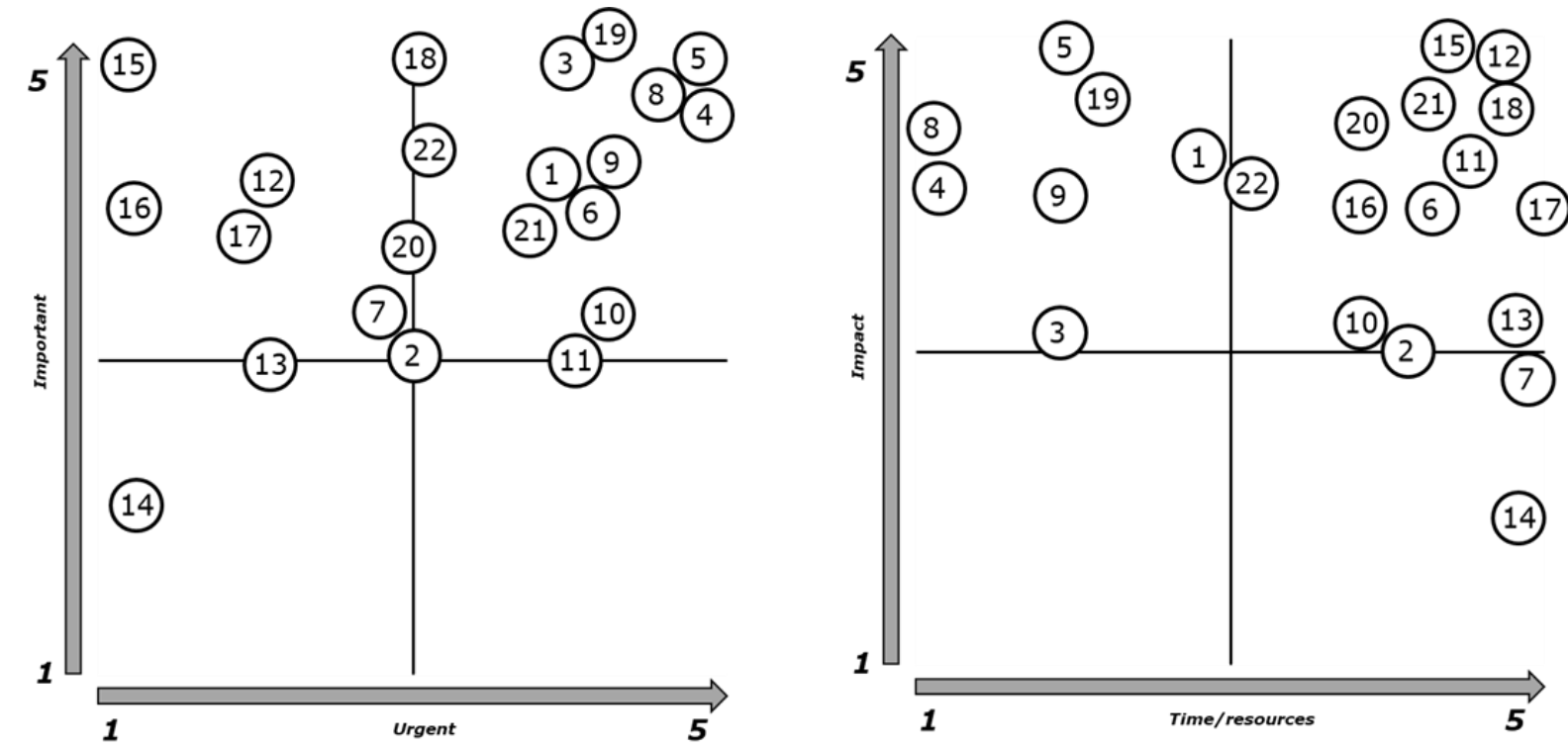

Figure 27: Support tool to prioritize projects, using the combinations of (left) importance and urgency, and (right) impact and required time/resource.

In the second step, we characterize each quadrant. For both sets of axes, we can distinguish four specific combinations of scores. The highest priority should be given to projects that are (A) important and urgent, and/or (B) high impact and low required time/resources. Especially the projects who appear in both can be considered as "low-hanging fruit" and or "no regret" projects. These projects are important to allow for next projects, although require only limited investments. Examples include the development of a method for litter in the water column and baseline measurements floating litter. Second highest priority should be given to projects that are (A) important, but less urgent and (B) high impact, but require more time/resources. These are typical projects with longer duration that require more careful planning and larger financial investment or commitment. Examples include long-term monitoring floating litter and determine mass balance and emissions. Finally, there are projects that are classified as less important and less impactful. These projects are interesting and will still compliment the other projects, but are not absolutely crucial for the successful design of the national monitoring strategy. Examples include projects related to sediment. Literature suggests that the accumulation in sediment may be limited, while sampling sediments is relatively resource-demanding. Such projects can therefore be considered as "nice to have", but not crucial. 

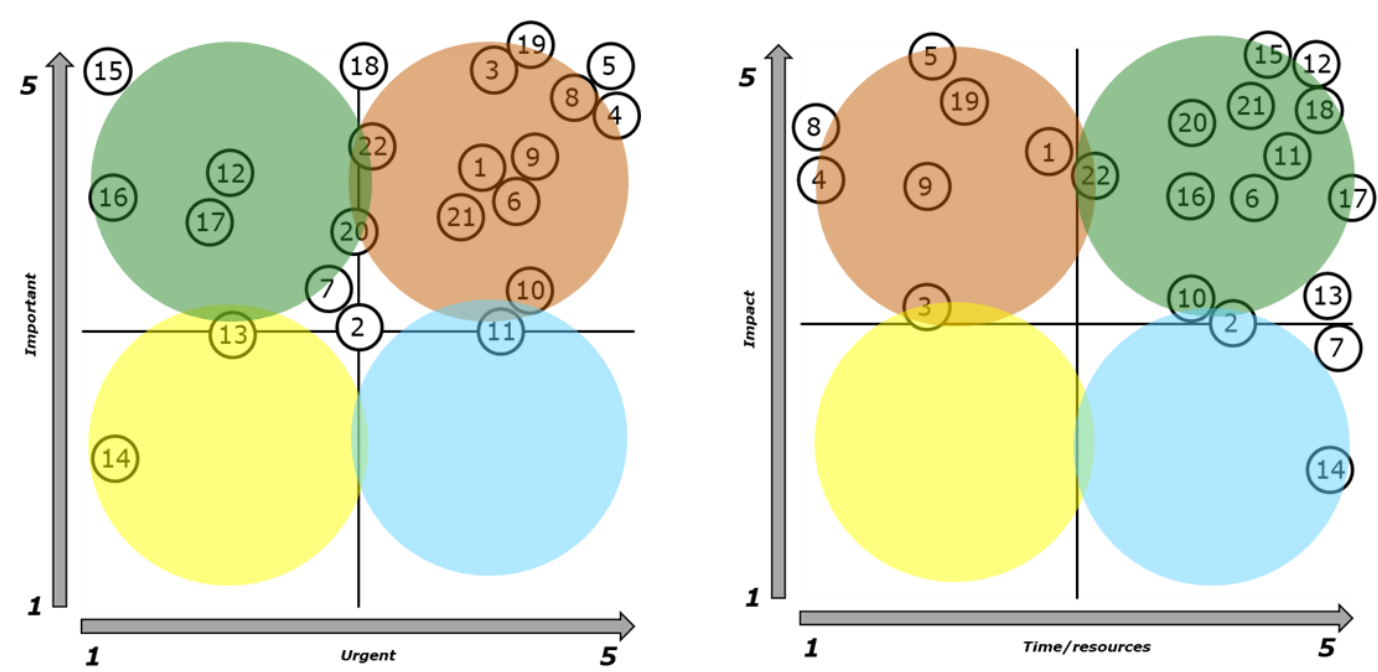

Figure 28: Final step to decide on what projects to do on the short term, the long-term, or not at all.

\subsection{Clustering projects}

To create some order in the (non-exhaustive) list of project proposals, we clustered the projects in six groups. Each cluster has an overarching theme, where projects can be added to or removed from. Clusters are based on the similar efforts required or overlap in theme. For example, all projects related to method development are clustered in "Innovative Sensing". The benefit of clustering is that for the national strategy development, not all individual projects have to be scheduled, and a clear timeline can be based on the project clusters.

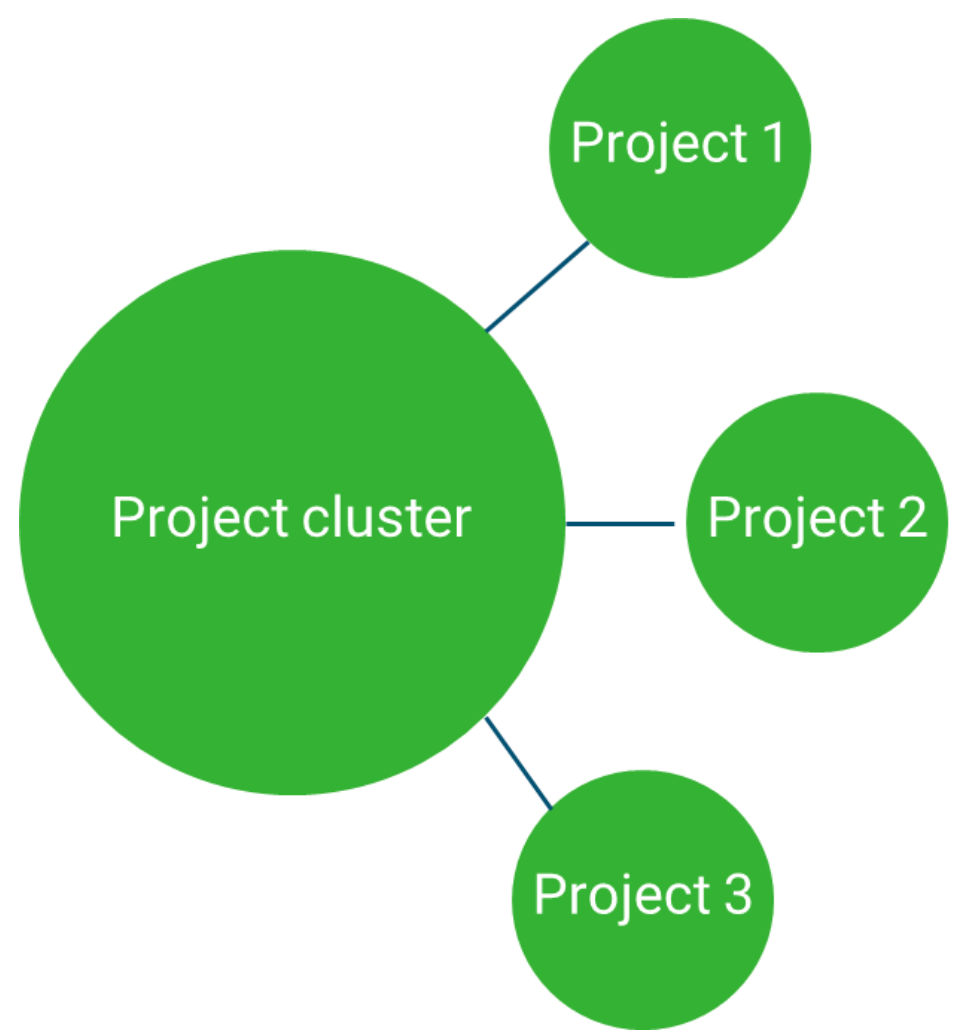

Figure 29: Project cluster - Aggregating projects with similar goals and approaches. Projects can be added and removed from clusters.

We identified six projects clusters: (1) Innovative Sensing, (2) Monitoring protocols, (3) National Baseline, (4) Long-term monitoring, (5) Collaboration \& Integration, and (6) Guidelines \& Solutions. Cluster 1 (innovative sensing) focuses on method development, testing and optimization. This includes developing 
the first method for consistent measurements of litter suspended in the water column. However, this can also include projects related exploring the use of new technology to replace or complement existing tested methods. Cameras and drones have been demonstrated as promising technologies for monitoring of floating and riverbank litter, but further work is required to test this for the Dutch rivers. Cluster 2 (Monitoring protocols) use the tested and proven methods to develop monitoring protocols. An example is a project to develop a method for determining emissions into the ocean. Such method will most likely be a combination of observations (visual counting from bridges, sampling of litter), models and statistics. The outcome of Cluster 2 includes concrete protocols that can be implemented in the national monitoring strategy. Cluster 3 (National Baseline) contains all projects related to establishing baseline values and first estimates of sources and most abundant items. The includes litter in all river compartments. Cluster 4 (Long-term monitoring) combines the results from Clusters 1-3 into long-term monitoring programs for specific river compartments, or indirectly measurable metrics, such as the mass balance and emissions into the ocean. Cluster 5 (Collaboration \& Integration) relates to all projects concerning collaboration within RWS and with local, national and international stakeholders. This includes harmonizing monitoring protocols and sharing data with other states within the Rhine, Meuse and Scheldt river basins. Projects focused on exploring including data from other parties (e.g. citizen science, local contractors or governments) are also part of this cluster. Cluster 6 (Guidelines \& Solutions) relates to all solution, guidelines and policy related goals. Projects are included on assessing effects of measures, determining norm and target values, and trend analyses. Note, the list of projects is not exhaustive, and new projects can be added.

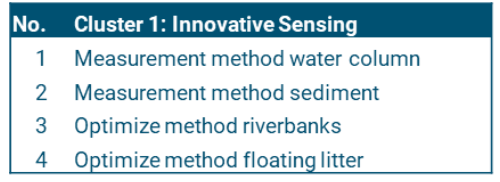

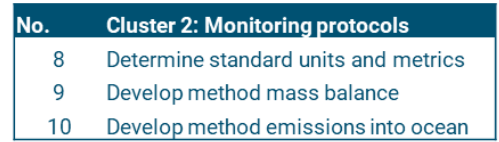

10 Develop method emissions into ocean

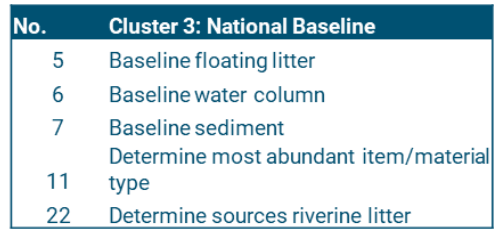

\begin{tabular}{|rl|}
\hline No. & Cluster 6: Guidelines \& Solutions \\
\hline 17 & Trend analysis riverine litter \\
18 & Quantify effect measures \\
19 & Determine norm and target values \\
\hline
\end{tabular}

19 Determine norm and target values

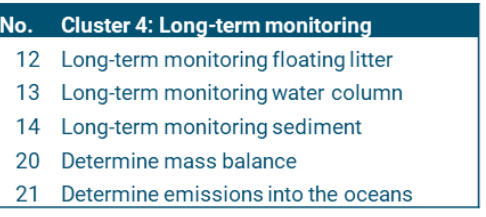

\begin{tabular}{|c|c|}
\hline No. & Cluster 5: Collaboration \& Integration \\
\hline 15 & Integrated long-term monitoring \\
\hline 16 & $\begin{array}{l}\text { Harmonization with neighbouring } \\
\text { regions }\end{array}$ \\
\hline & Investigate the role of citizen science in \\
\hline 24 & $\begin{array}{l}\text { Investigate the role of alternative data } \\
\text { sources in long-term monitoring strategy }\end{array}$ \\
\hline
\end{tabular}

Figure 30: Proposed project clusters. Note that the projects attributed to each cluster is nonexhaustive and can be adjusted based on new insights, priorities and goals.

\subsection{Timeline for national monitoring strategy}

In Figure 31 we present a tentative timeline for the six project clusters, distributed over the short term, medium term and long term. On the short time, the highest priority should be given to the first two clusters: (1) Innovative sensing and (2) Monitoring protocols. No monitoring activities can be planned until measurement methods and protocols have been developed and tested for the Dutch rivers. The only exception is riverbank litter, for with a robust method, protocol and strategy has been developed and implemented. A logical next step is to prepare the monitoring protocol for floating litter monitoring. The methods are available and tested, and there are plenty of measurement locations identified for the Dutch rivers. Once this is finalized, this can be used for cluster 3, the National Baseline. For cluster three, again the riverbanks are excluded as ample data are available. The National Baseline will probably be executed in steps, starting with floating litter, followed by water column litter and litter in sediments. Once the first results are in from Cluster 3, a start can be made with clusters 4 and 5 . Specifically, long-term monitoring can be continued for the riverbanks, and expanded with floating litter. For sustainable long-term monitoring, it is also crucial to keep an open channel with relevant local, national and international partners and stakeholders. This will allow harmonization of protocols, data sharing and dissemination of results in an easy phase. Once considerable steps have been made in clusters 1 and 2, and the first baseline data is collected, cluster 6 (Guidelines \& Solutions) should also start. Within this cluster actions can be made 
related to definition of norm and target values, and the first multi-year datasets may be explored to develop tools for trend analysis and the evaluation of measures. It is expected that Clusters 1-3 are largely done within 3-4 years. Clusters 4-6 primarily focus on long-term activities, and are therefore foreseen to continue to at least 2030 , if not longer.

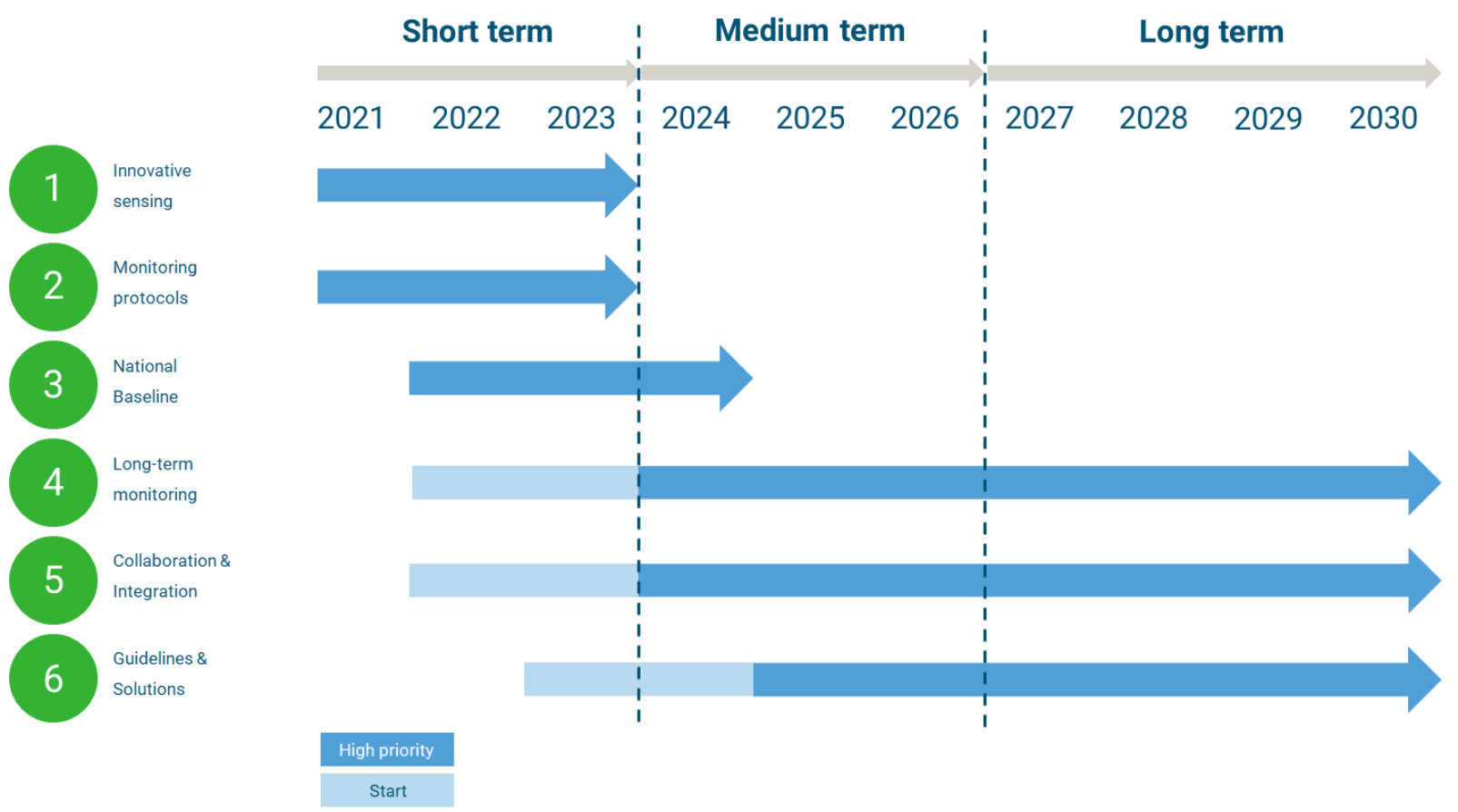

Figure 31: Proposed timeline for clusters, distributed over short term, medium term and long term.

\subsection{Riverine litter monitoring is an iterative process}

The Roadmap is no linear solution. On the contrary, it offers a flexible framework that allows for the incorporation of new insights, monitoring goals, priorities, and data (Figure 32). Design and optimization of a national riverine litter monitoring strategy requires an iterative approach. The most important is, however, to make a start with projects that have high priority at this moment. When new insights or answers to open questions have been generated, it can be assessed whether the monitoring goals have been achieved. And whether the goals are still relevant. After this a new cycle can start. From the new or revised monitoring goals, new open questions can be formulated. Using the Roadmap the paths from current state to answers can be found. The routes are used to formulate new projects, which can be prioritized and clustered based on the current context and available resources. Finally, the clusters can be planned and projects can be executed. After this, the next iteration will follow. 


\section{Monitoring goals}
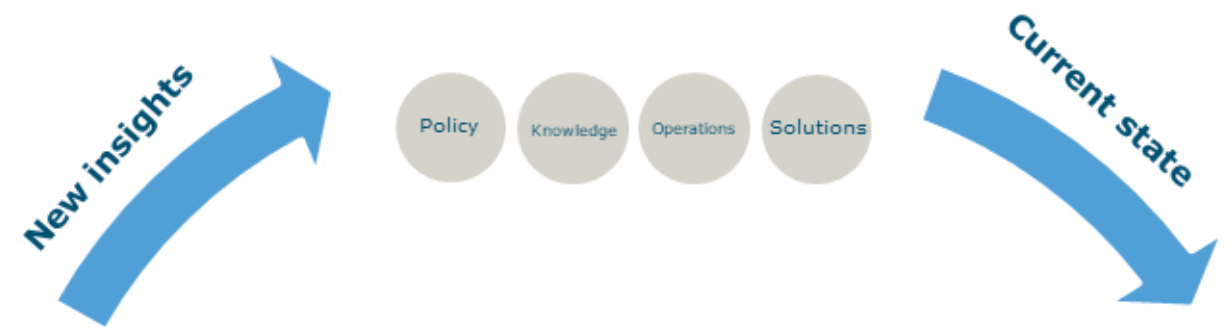

\section{Timeline}
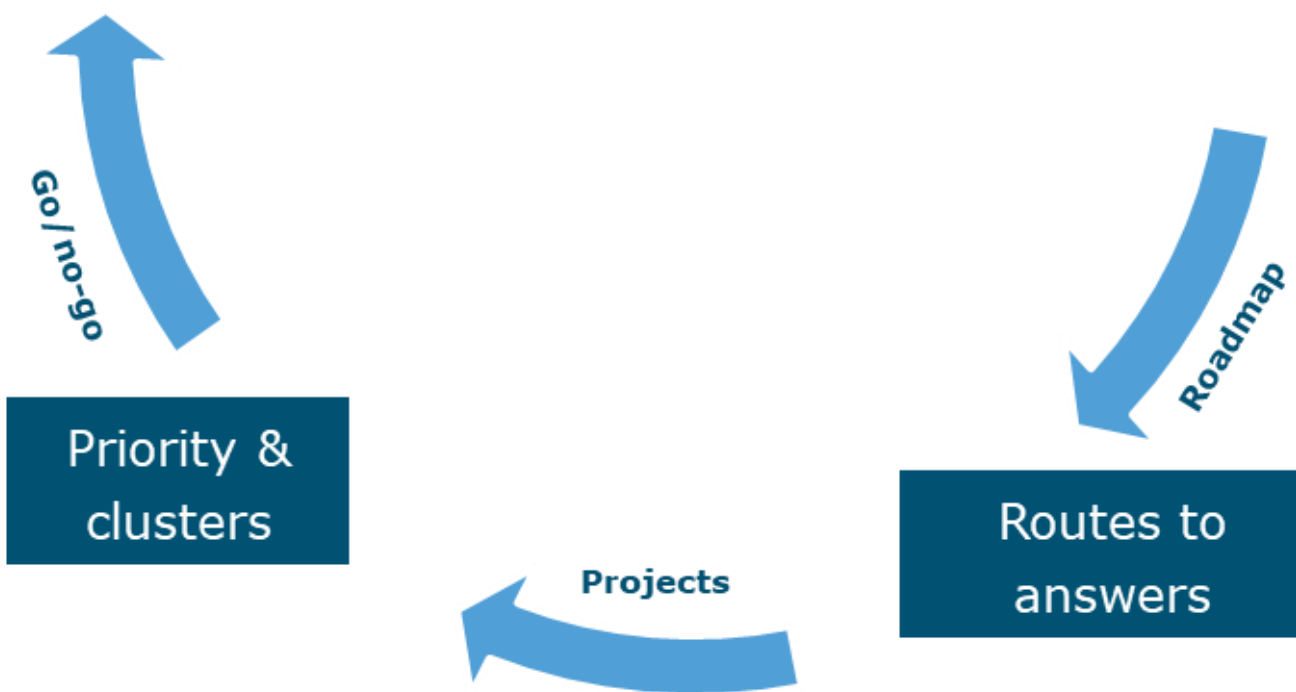

\section{Routes to}

\section{answers}

Figure 32: The cycle of defining monitoring goals, formulating open questions, selecting routes to answers, prioritizing and clustering projects, and planning and executing projects. This emphasizes the iterative nature of riverine litter monitoring. 


\section{$7 \quad$ Conclusions and recommendations}

\subsection{Conclusions}

With this Roadmap we present a practical tool for the design of a national riverine litter monitoring strategy. We emphasize that there is no single solution or path forward. Depending on the defined goals, guidelines and new insights, the actual selection of projects and their respective timelines may change. The Roadmap provides guidance on what questions can be answered by choosing a specific route. Alternatively, the Roadmaps shows what steps are required to arrive at an answer to a specific question.

We defined four goals for the national riverine litter monitoring strategy: (1) policy, (2) knowledge development, (3) operations, and (4) solutions. Monitoring is required for development of data-driven policy. Quantitative data will contribute to setting and evaluating guidelines, norm and target values of litter in rivers. Sources, sinks and transport pathways remain unclear, and data will contribute to increasing the understanding of these aspects. River quality monitoring is an intrinsic task of RWS, and current activities may be extended with litter monitoring. Finally, reliable monitoring data is necessary to evaluate any solution, ranging from policy to waste collection in rivers.

The Roadmap consists of three levels: (1) monitoring methods, (2) baseline, and (3) long-term monitoring. At each level, specific questions can be answered if the level is achieved for specific river components. For examples at higher levels, the previous levels need to be unlocked first. This created a clear step-wise approach to solve open challenges. For example, to evaluate the effect of measures, all levels are required (method, baseline, long-term data). In contrast, questions related to methods and protocols remain on the first level.

A set of 24 project proposals has been presented to fill out the missing elements in the Roadmap. The projects are clustered in six categories. Clusters are based on the overlap in level and required approach. Individual projects can be added or removed in the detailed planning of these projects. On the short term (1-3 years), the highest priority should be given to cluster 1 (Innovative sensing) and 2 (monitoring protocols). On the medium term, national baseline (cluster 3 ) measurements should be done for all relevant river compartments (floating, water column, sediment). At the same time, clusters 4 (Collaboration \& Integration) and 5 (Guidelines \& Solutions) can be started, although results from previous clusters are required before they can be fully scheduled. These clusters therefore remain for the long-term planning ( $>5$ years).

With the Roadmap we aim to provide a new tool to support decision-making and planning of specific projects. The specific questions and projects are not exhaustive, and the Roadmap is a flexible framework that allows to add and remove elements based on new insights, the available resources, and other relevant changes. Riverine litter monitoring remains an iterative process, and we hope that the Roadmap will contribute to taking a first step in the right direction.

\subsection{Recommendations}

Based on the current state of monitoring in Dutch rivers, the outcomes of the expert survey, and the Roadmap, we present a set of recommendations. These recommendations may support setting priorities in next steps for action.

\section{Start simple}

In the field of riverine litter monitoring it is tempting to focus on high-tech solutions. However, we strongly encourage to start simple, and make sure the basics are covered. This includes setting up a monitoring network for floating litter. The methods required for floating litter monitoring are tested and readily available. In parallel further development of high-tech monitoring methods can only be praised, but one should not expect miracles on the short term. Developments of image-based monitoring techniques, such as cameras and drones, are promising, but should be considered as complementary. For example, specific 
areas may be selected to be monitored, but lack infrastructure or safety. Here, conventional methods may not be applicable, and other options can be considered.

\section{National baseline floating litter}

Based on literature it is likely that floating litter and litter on riverbanks account for most of the total litter in river systems. For riverbanks, data have been collected on a national scale for several years already. As a result, many new insights on abundance, sources and transport mechanisms have been generated. We therefore strongly encourage to start with the national baseline for floating litter. Studies on European and global scales have demonstrated that with simple visual counting measurements, a good estimate of the floating litter transport, spatiotemporal variation and composition can be made.

\section{Invest in method development}

In contrast to floating and riverbank litter, no methods are available for monitoring litter in the water column or sediment. Some first tests have been done with for example subsurface nets, echo sounding and sediment sampling, but no method has been thoroughly tested for application in Dutch rivers. The inability to measure (level 1 in the Roadmap), prevents the planning of a national baseline or long-term monitoring strategy (levels 2 and 3 in the Roadmap). To date, method development is largely an academic exercise. We encourage RWS to play a more leading and supporting role to boost these activities.

\section{Integration with RWS monitoring}

Riverine litter monitoring may be advanced through integration with RWS monitoring infrastructure. Integration can be done through joint planning of monitoring activities, but also through data collection, analysis and visualization. The RWS monitoring dashboard (waterinfo.rws.nl) has recently been expanded with beach litter monitoring data. We encourage to do the same with riverine litter monitoring data. The advantages are threefold. First, this facilitates rapid dissemination of the data and results, reaching stakeholders and citizens. Second, litter data can easily be compared with other available RWS data, such as river water level, discharge, and flow velocity. Finally, a central location for the storage of litter data allows for meaningful trend analysis and hotspot analysis. 


\section{References}

All Seas (n.d.). Accessed on 22-10-2020 via: https://allseas.com/project/catchy/

Blueocean. (n.d.). Accessed on 05-11-2020 via: https://blueocean.net/powerful-images-of-plasticpollution-go-viral/

Borrelle, S. B., Ringma, J., Law, K. L., Monnahan, C. C., Lebreton, L., McGivern, A., ... \& Eriksen, M. (2020). Predicted growth in plastic waste exceeds efforts to mitigate plastic pollution. Science, 369(6510), 1515-1518.

Broere, S. (2020). The sound of plastic: A proof-of-concept for detecting suspended riverine macroplastics with echo sounding. TU Delft master Thesis.

Bruge, A., Barreau, C., Carlot, J., Collin, H., Moreno, C., \& Maison, P. (2018). Monitoring litter inputs from the Adour River (Southwest France) to the marine environment. Journal of Marine Science and Engineering, 6(1), 24.

Clearrivers (n.d.). Accessed on 22-10-2020 via: https://www.clearrivers.eu/what-we-do

González-Fernández, D., \& Hanke, G. (2017). Toward a harmonized approach for monitoring of riverine floating macro litter inputs to the marine environment. Frontiers in Marine Science, 4, 86.

González-Fernández, D., Hanke, G., Kideys, A., Navarro-Ortega, A., Sanchez-Vidal, A., Brugère, A., ... \& Barcelo, D. (2018). Floating Macro Litter in European Rivers-Top Items (Doctoral dissertation, European Commission-DG Joint Research Centre).

Great Bubble Barrier (n.d.). Accessed on 22-10-2020 via: https://thegreatbubblebarrier.com/en/

Honingh, D., van Emmerik, T., Uijttewaal, W., Kardhana, H., Hoes, O., \& van de Giesen, N. (2020). Urban river water level increase through plastic waste accumulation at a rack structure. FrEaS, 8, 28.

Interreg. (n.d.) LIVES. Accessed on 06-11-2020 via: https://www.interregemr.eu/projects/lives-1-en

Kiessling, T., Knickmeier, K., Kruse, K., Brennecke, D., Nauendorf, A., \& Thiel, M. (2019). Plastic Pirates sample litter at rivers in Germany-Riverside litter and litter sources estimated by schoolchildren. Environmental Pollution, 245, 545-557.

Landman, H., and Pikaar, R. (2019). Eindrapportage Shoreliner Lekhaven Rotterdam. Tauw, Kenmerk: R002-1261397HLM-V02-nnc-NL. doi: 10.1016/j.envpol.2018.02.005

Lebreton, L., \& Andrady, A. (2019). Future scenarios of global plastic waste generation and disposal. Palgrave Communications, 5(1), 1-11.

Lebreton, L. C., Van Der Zwet, J., Damsteeg, J. W., Slat, B., Andrady, A., \& Reisser, J. (2017). River plastic emissions to the world's oceans. Nature communications, 8, 15611.

Mihai, F. C. (2018). Rural plastic emissions into the largest mountain lake of the Eastern Carpathians. Royal Society Open Science, 5(5), 172396.

Noria (n.d.). Accessed on 22-10-2020 via: https://www.noria.earth/

Tasseron, P., Zinsmeister, H., Rambonnet, L., Hiemstra, A. F., Siepman, D., \& van Emmerik, T. (2020). Plastic Hotspot Mapping in Urban Water Systems. Geosciences, 10(9), 342.

Nurhati, I. S., \& Cordova, M. R. (2020). Marine plastic debris in Indonesia: Baseline estimates (2010-2019) and monitoring strategy (2021-2025). Marine Research in Indonesia, 45(2).

Pabortsava, K., \& Lampitt, R. S. (2020). High concentrations of plastic hidden beneath the surface of the Atlantic Ocean. Nature communications, 11(1), 1-11.

Peng, G., Bellerby, R., Zhang, F., Sun, X., \& Li, D. (2020). The ocean's ultimate trashcan: Hadal trenches as major depositories for plastic pollution. Water research, 168, 115121. 
Petten, L., Schalekamp, J., Viool, V., Gupta, A. (2020). The price tag of plastic pollution - An economic assessment of river plastic. Deloitte. Accessed on 04-11-2020 via: https://www2.deloitte.com/nl/nl/pages/strategy-analytics-and-ma/articles/the-price-tag-of-plasticpollution.html

Plastic Pirates (n.d.). Campaign materials. Wissenschaftjahr Deutschland. Accessed on 22-10-2020 via: https://www.wissenschaftsjahr.de/2016-17/weiterfuehrende-informationen/englisch/plasticpirates/downloads.html

Rech, S., Macaya-Caquilpán, V., Pantoja, J. F., Rivadeneira, M. M., Campodónico, C. K., \& Thiel, M. (2015). Sampling of riverine litter with citizen scientists-findings and recommendations. Environmental monitoring and assessment, 187(6), 335.

Schöneich-Argent, R. I., Dau, K., \& Freund, H. (2020). Wasting the North Sea?-A field-based assessment of anthropogenic macrolitter loads and emission rates of three German tributaries. Environmental Pollution, 114367.

Scouts4Science (n.d.). Accessed on 22-10-2020 via: https://www.scouts4science.nl/

Schmidt, C., Krauth, T., \& Wagner, S. (2017). Export of plastic debris by rivers into the sea. Environmental science \& technology, 51(21), 12246-12253.

Van der Wal, M., van der Meulen, M., Tweehuijsen, G., Peterlin, M., Palatinus, A., Virsek, M., Coscia, L., Krzan, A. (2015). SFRA0025: Identification and Assessment of Riverine Input of (Marine) Litter - Final report for the European Commission DG Environment under Framework. Contract No ENV.D.2/FRA/2012/0025

van Emmerik, T., Vriend, P., \& Roebroek, J. (2020a). An evaluation of the River-OSPAR method for quantifying macrolitter on Dutch riverbanks. Wageningen University.

van Emmerik, T., Roebroek, C. T. J., de Winter, W., Vriend, P., Boonstra, M., \& Hougee, M. (2020b). Riverbank macrolitter in the Dutch Rhine-Meuse delta. Environmental Research Letters.

van Emmerik, T., Seibert, J., Strobl, B., Etter, S., Den Oudendammer, T., Rutten, M., ... \& van Meerveld, I. (2020c). Crowd-based observations of riverine macroplastic pollution. Frontiers in Earth Science, 8, 298.

van Emmerik, T., Kieu-Le, T. C., Loozen, M., van Oeveren, K., Strady, E., Bui, X. T., ... \& Schwarz, A. (2018). A methodology to characterize riverine macroplastic emission into the ocean. Frontiers in Marine Science, 5, 372.

van Emmerik, T., \& Schwarz, A. (2020). Plastic debris in rivers. Wiley Interdisciplinary Reviews: Water, 7(1), e1398.

Vriend, P., Roebroek, C.T.J., van Emmerik, T. (2020a). Same but different: A framework to design and compare riverbank plastic monitoring strategies. Frontiers in water, 1, 29.

Vriend, P., Van Calcar, C., Kooi, M., Landman, H., Pikaar, R., \& Van Emmerik, T. (2020b). Rapid assessment of floating macroplastic transport in the Rhine. Frontiers in Marine Science, 7, 10. 
Annex 1 Rijkswaterstaat Expert Survey

\begin{tabular}{|c|c|}
\hline & Vraag \\
\hline 1 & Omschrijf kort uw eigen expertise \\
\hline 2 & $\begin{array}{l}\text { Omschrijf kort uw eigen werkzaamheden met betrekking tot zwerfafval/plastics (in } \\
\text { rivieren). }\end{array}$ \\
\hline 3 & $\begin{array}{l}\text { Waarom is Rijkswaterstaat volgens u geïnteresseerd in monitoring van } \\
\text { zwerfafval/plastics in rivieren? }\end{array}$ \\
\hline 4 & $\begin{array}{l}\text { Het ontwerpen van een passende monitoringsstrategie is erg afhankelijk van het doel. } \\
\text { Welke van de onderstaande redenen acht u belangrijk voor een nationale } \\
\text { monitoringsstrategie? (meerdere antwoorden mogelijk) }\end{array}$ \\
\hline 5 & $\begin{array}{l}\text { Welke van de onderstaande indicatoren moeten volgens u gemeten worden als } \\
\text { onderdeel van de nationale monitoringsstrategie (plastic) zwerfafval? (meerdere } \\
\text { antwoorden mogelijk) }\end{array}$ \\
\hline 6 & Hoeveel kennis heeft RWS over drijvend zwerfafval/plastics in rivieren? \\
\hline 7 & Hoeveel kennis heeft RWS over zwerfafval/plastics op rivieroevers? \\
\hline 8 & $\begin{array}{l}\text { Hoeveel kennis heeft RWS over zwerfafval/plastics in de waterkolom (onder het } \\
\text { oppervlakte)? }\end{array}$ \\
\hline 9 & Hoeveel kennis heeft RWS over zwerfafval/plastics in riviersediment? \\
\hline 10 & $\begin{array}{l}\text { Van welke bestaande andere monitoringsprogramma's in Nederlandse rivieren kan } \\
\text { RWS lessen overnemen en waarom? Denk aan o.a. microplastic, sedimenttransport, } \\
\text { vervuiling, hydrologie. }\end{array}$ \\
\hline 11 & Hoe zouden micro- en macroplasticmonitoring elkaar kunnen versterken en waarom? \\
\hline 12 & $\begin{array}{l}\text { Hoe zou de samenwerking met buurlanden en buurregio's de afvalmonitoringsstrategie } \\
\text { in Nederlandse rivieren kunnen versterken? }\end{array}$ \\
\hline 13 & Hoe kunnen een regionale en nationale zwerfafval/plastics aanpak elkaar versterken? \\
\hline 14 & $\begin{array}{l}\text { Waar staat volgens u RWS in } 2030 \text { m.b.t. (plastic) zwerfafvalmonitoring in Nederlandse } \\
\text { rivieren? }\end{array}$ \\
\hline 15 & $\begin{array}{l}\text { Wat zijn volgens u de grootste uitdagingen en vragen m.b.t. zwerfafvalmonitoring? } \\
\text { (denk bijvoorbeeld aan financieel, organisatorisch, technisch en politiek) }\end{array}$ \\
\hline 16 & $\begin{array}{l}\text { Hoe kan de bestaande RWS-monitoringsactiviteiten en de RWS-infrastructuur ingezet } \\
\text { worden voor de monitoring van zwerfafval/plastics? }\end{array}$ \\
\hline 17 & $\begin{array}{l}\text { Welke doelen en tussendoelen zijn nodig voor de realisatie van in de (plastic) } \\
\text { zwerfafvalmonitoring? }\end{array}$ \\
\hline 18 & $\begin{array}{l}\text { Wat zijn resultaten die monitoringsstrategie moet opleveren voor korte (1-3 jaar), } \\
\text { middellange } 3-5 \text { jaar en lange (>5 jaar) termijn, en wat moet er met deze resultaten } \\
\text { kunnen worden gedaan? }\end{array}$ \\
\hline 19 & $\begin{array}{l}\text { Wij zouden graag feedback ontvangen op de (voorlopige) Routekaart. Bent u } \\
\text { geïntereseerd om mee te werken aan een tweede, technisch inhoudelijkere rondvraag? } \\
\text { Deze zal eind september verstuurd worden. }\end{array}$ \\
\hline 20 & g overige opmerkingen of suggesties? \\
\hline
\end{tabular}


